\title{
Estimation of Glacier Ice Extinction Using Long-Wavelength Airborne Pol-InSAR
}

\author{
Jayanti J. Sharma, Member, IEEE, Irena Hajnsek, Senior Member, IEEE, \\ Konstantinos P. Papathanassiou, Senior Member, IEEE, and Alberto Moreira, Fellow, IEEE
}

\begin{abstract}
In the recent years, there has been increased interest in using synthetic aperture radar (SAR) to study and monitor glaciers and ice sheets for glaciological and climate change research. This paper describes the estimation of ice extinctions through the modeling of polarimetric interferometric SAR (Pol-InSAR) coherences as a combination of a surface contribution (from the snow-firn interface and wind-induced sastrugi features) and a volume response. Ground-to-volume scattering ratios derived from a novel polarimetric decomposition are used in conjunction with Pol-InSAR coherence magnitudes to invert the extinction of the ice layer. The inversion is performed for experimental airborne Pol-InSAR data at $L$-band and P-band acquired by the German Aerospace Center's (DLR) E-SAR system over the Austfonna ice cap in Svalbard, Norway, as part of the 2007 IceSAR campaign. Extinction dependences on frequency and glacier facie are investigated, and validation is performed comparing ground-penetrating radar data to SAR backscatter and extinction values. Best extinction results are obtained at shallow incidence angles with small wavenumbers and for low ground-tovolume scattering ratios. For swath areas in mid range to far range, accuracies of $25 \%$ in extinction are anticipated when averaging over 100 effective looks for a four-baseline inversion constraining solutions to vertical wavenumbers of $0.01 \leq k_{z} \leq 0.1$. To allow inversion using single-baseline Pol-InSAR, the proposed model is of limited complexity. Suggested extensions for a more realistic scattering scenario include incorporating multiple englacial ice scattering layers and improving the way multiple baselines are combined.
\end{abstract}

Index Terms-Extinction, glacier, land ice, polarimetric synthetic-aperture-radar interferometry (Pol-InSAR).

\section{INTRODUCTION}

$\mathbf{O}$ VER the last decades, the use of satellite remote sensing has revolutionized the field of glaciology through dramatic improvements in the scale and in the temporal and spatial resolutions of cryospheric observations. However, due

Manuscript received July 21, 2010; revised April 13, 2011, June 17, 2011, August 30, 2011, and June 29, 2012; accepted August 11, 2012. Date of publication December 10, 2012; date of current version May 16, 2013. This work was supported in part by the Microwaves and Radar Systems Institute of the German Aerospace Center (DLR), by the German Academic Exchange Service (DAAD), and the European Space Agency under Contract 20655/07/NL/CB.

J. J. Sharma is with MDA Systems Ltd., Richmond, BC V6V2J3, Canada (e-mail: jasharma@mdacorporation.com).

I. Hajnsek is with the Microwaves and Radar Institute, German Aerospace Center (DLR), 82230 Wessling, Germany, and also with the Institute of Environmental Engineering, Eidgenössische Technische Hochschule Zürich, 8093 Zurich, Switzerland (e-mail: irena.hajnsek@dlr.de).

K. P. Papathanassiou and A. Moreira are with the Microwaves and Radar Institute, German Aerospace Center (DLR), 82230 Wessling, Germany (e-mail: kostas.papathanassiou@dlr.de; alberto.moreira@dlr.de).

Color versions of one or more of the figures in this paper are available online at http://ieeexplore.ieee.org.

Digital Object Identifier 10.1109/TGRS.2012.2220855 to the medium's complexity, as well as to the limited information retrieved for a single resolution element, synthetic aperture radar (SAR) backscattering from ice remains poorly understood, including the relative importance of scattering from surface and volume layers, and dependences on frequency and glacier zone.

The greatest effort to date has been on the use of singlepolarization SAR backscattering coefficients for glacier studies. Some success has been achieved using SAR intensities at Xand C-bands to map glacier melt zones and their temporal variations [1], for the velocity estimation of fast-moving glaciers using feature tracking [2] and to determine snow accumulation rates [3], [4]. However, accumulation inversion is generally performed without an established physical model, such that its validity and performance depend on the incidence angle and the test site, thus limiting model robustness and generality. In addition, since higher accumulation rates and larger snow grain sizes both contribute to increased SAR intensities [5], there is an ambiguity in the interpretation of the backscattering coefficient.

Polarimetric SAR (PolSAR) offers additional observables to characterize glacier scenes, although publications to date have emphasized descriptions of polarimetric properties [6], [7] and discrimination between snow and bare ice areas [8], [9] rather than the modeling of geophysical parameters. For long wavelengths such as L-band and P-band, which penetrate deep into the ice and for which both surface and volume scattering contributions are significant, PolSAR observables in conjunction with a decomposition model have been used to separate scattering mechanisms in [10]. The results indicate sensitivity of coherent SAR observables at low frequencies to physical properties of the ice volume; however, the observation space provided by a single polarimetric acquisition does not allow the inversion of realistic (in terms of complexity) ice scattering models. In the presence of volume scattering, one way to extend the observation space is to consider interferometric measurements.

Interferometric SAR (InSAR) further expands the observation space by yielding estimates of the complex coherence. Spaceborne repeat-pass SAR interferometry has been widely applied to measure glacier topography and displacements (related to velocity) at accuracies of centimeters to meters [11]-[13]. InSAR also provides information on the vertical distribution of scatterers in the ice, which has been used to parameterize the relation between interferometric coherence and penetration depth [14], or snow accumulation [5].

Penetration depth is related to the signal extinction rate, which is a relevant parameter for glaciologists as it contains 
information on the density and the internal ice structure. Extinctions may be useful for characterizing regions of increased volume scatter [15], which are related to the presence of melt structures (i.e., ice structures formed by melting and refreezing processes), and could be thus used to monitor interannual changes and ice structure formation within glacier and ice volumes [16]. Of particular interest is the near-surface (upper 10-30 m, which can be penetrated by radar wavelengths [15]), whose englacial structures reflect seasonal and interannual climatic fluctuations [15]. Even small differences in the accumulation rate can result in significant differences in ice grain size and density over time [3], where the relation between grain size, ice density, and extinction was examined in [5] and [15].

Areas with higher or lower extinction (and hence different ice structures) correspond to different glacier facies or melt zones, where monitoring the extent of the various melt zones is a key requirement for detecting any fluctuations that may be occurring in the polar regions as a result of climatic change [17]. Extinctions may also aid in better understanding ice sheet velocities derived from differential InSAR (DInSAR); as the vertical velocity distribution in ice sheets is, in general, nonuniform [18], the estimated phase center velocity is different from the surface velocity. This difference can be significant, particularly at lower radar frequencies due to deeper penetration. This effect has to be accounted for when velocity fields derived from different wavelengths are combined. At the same time, seasonal variations in the penetration depth bias the estimation of ice sheet velocities from DInSAR. Thus, extinction's close relationship to the penetration depth [19] could aid in the interpretation and the depth localization of ice sheet velocities derived from repeat-pass InSAR.

Preliminary investigations into the relation between coherence and ice extinction were conducted in [14] in which the ice was modeled as a homogeneous, lossy, and infinite scattering volume. However, polarimetric effects were not included and surface scattering, which is likely to significantly contribute to overall backscatter [20], [21], was neglected. In [5], this model was extended to use both coherence magnitude and backscatter to invert grain size and accumulation rate in the dry-snow zone of Greenland, where the need to model both surface and volume scattering mechanisms for consistency between modeled and observed results at C-band was clearly demonstrated. However, the model requires knowledge of temperature, surface roughness, and ice layering, such that its application is restricted to specific sites and to higher (X-and C-band) frequencies. A model exploiting polarimetric properties and requiring limited a priori information could prove useful for further investigations of the glacier subsurface with SAR.

In the last decade, polarimetric interferometric SAR (PolInSAR) has become an established technique for the extraction of geophysical parameters from volume scatterers, particularly for vegetation applications. However, the use of PolInSAR over glaciers to date is restricted to a small number of airborne studies [22]-[24] due to limited data availability and to difficulties in validation. Stebler et al. [22] describe Pol-InSAR signatures at L-band and P-band over an alpine glacier, although no model is suggested to explain polarization dependences in the backscatter and interferometric coherence.
Pol-InSAR coherences at L-band over Greenland are presented in [23], and several models are examined in [24], although no physically realistic model consistent with observed coherence magnitude and phase was found.

This paper investigates experimental data acquired as part of the IceSAR campaign, where the suitability of simple scattering models to interpret and invert Pol-InSAR data is examined. The goal of this paper is to develop and invert a scattering model parameterizing Pol-InSAR observables in terms of glacial properties. The polarimetric decomposition model from [10] is used to separate volume and surface scattering components, where a detailed analysis has been presented in [10]. Building upon these results, in this paper, a model is proposed relating interferometric coherence magnitude, extinction, and groundto-volume scattering ratios derived from the polarimetric decomposition. The extinction modeling approach is presented in Section II, and its estimation accuracy is evaluated in Section III. Experimental data collected at L-band and P-band using the German Aerospace Center's (DLR) airborne E-SAR system and ground-penetrating radar (GPR) data are described in Section IV. The SAR data are used in Section V to invert extinctions for the Austfonna ice cap in Svalbard, Norway. Results are validated against published extinction values and the GPR data in Section VI, and a review and a discussion of the results are given in Section VII.

\section{Modeling Glacier ICE Extinctions}

Extinction accounts for the combined effects of absorption and scattering in a medium and may be expressed in terms of the penetration depth $d_{\text {pen }}$ at which the one-way power falls to $1 / e$ [19], i.e.,

$$
\kappa_{e}=-\cos \left(\theta_{r}\right) / d_{\text {pen }}
$$

where the $\cos \left(\theta_{r}\right)$ factor accounts for the off-vertical travel distance of the wave within the medium, and $\theta_{r}$ is the incidence angle after refraction. $\kappa_{e}$ is the power extinction coefficient in units of Nepers per meter, although it is conventionally quoted in decibels per meter. In reality, extinction is depth-dependent due to changes in density, temperature, and melt structures with depth. Here, an effective extinction for the near-surface is considered, which can be regarded as a weighted value integrated from the surface to the depth of propagation. Electromagnetic models are developed for long-wavelength microwaves, i.e., L-band and P-band, with center frequencies of 1.3 and $0.35 \mathrm{GHz}$, respectively. Liquid water content has a profound impact on the dielectric properties of ice and snow, and throughout this paper, winter and early spring conditions without melt are assumed, such that the moisture content can be considered negligible. A discussion on the influence of liquid water content can be found in [25] and [26].

\section{A. Coherence Model for Glacier Ice}

A simple model relating extinction and interferometric coherence is proposed based on the work in [14] and [24]. As in [14], the ice volume is modeled as a semi-infinite half-space 


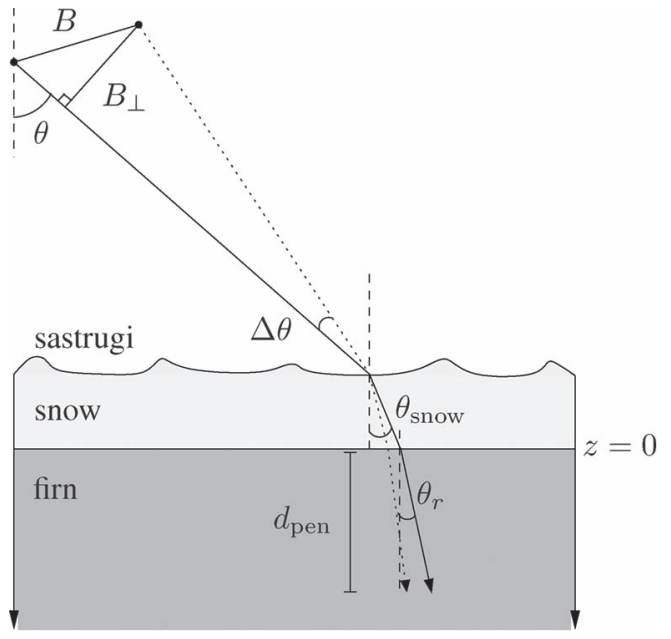

Fig. 1. InSAR geometry (not to scale) for a simplified glacier scenario assuming an infinite uniform volume with constant firn density.

consisting of a uniform distribution of scatterers embedded in a medium with dielectric constant $\varepsilon_{r} \simeq 2.8$ (see Appendix B). The near-surface is assumed to consist of firn (material in an intermediate stage between snow and ice). To minimize model complexity and reduce the number of unknowns, a uniform firn density is assumed. For the Svalbard test sites of interest in this paper, firn densities of $800 \mathrm{~kg} / \mathrm{m}^{3}$ are reached between 2.5 and $5 \mathrm{~m}$ of depth based on neutron probe density measurements [16]. Thus, for penetration depths of tens of meters, the uniform density simplification is deemed acceptable; this assumption breaks down, however, for areas such as the dry snow zones in central Greenland and Antarctica, where significant density changes are observed over tens of meters of depth.

The firn volume extends from the snow-firn surface (located at $z=0$ ) downward with radar viewing geometry given in Fig. 1. Above the firn is a layer of snow, which is punctuated by wind-induced features known as sastrugi [27] at the air-snow interface. The two radar acquisitions are separated by a spatial baseline $B$ (with effective baseline $B_{\perp}=B \cos \theta$ perpendicular to the line of sight), which, for incidence angle $\theta$, corresponds to a vertical wavenumber in free space of $k_{z}=$ $(4 \pi \Delta \theta) /(\lambda \sin \theta)$ [28]. $\lambda$ is the wavelength in free space, and $\Delta \theta=\theta_{2}-\theta_{1} \simeq B_{\perp} / R$, where $R$ is the slant range to the resolution cell of interest. As the wave enters the snow, it is refracted at an angle $\theta_{\text {snow }}$ to the vertical and is refracted once more to $\theta_{r}$ in the firn volume according to Snell's law. The difference in look angles from each antenna is $\Delta \theta$ in air and $\Delta \theta_{r}$ in the volume (not shown in Fig. 1), and $d_{\text {pen }}$ is the penetration depth in the ice volume.

The complex coherence $\gamma$ is given by the normalized cross correlation of two polarimetric SAR images $s_{1}(\vec{w})$ and $s_{2}(\vec{w})$, i.e.,

$$
\gamma(\vec{w})=\frac{\left\langle s_{1}(\vec{w}) s_{2}^{*}(\vec{w})\right\rangle}{\sqrt{\left\langle s_{1}(\vec{w}) s_{1}^{*}(\vec{w})\right\rangle\left\langle s_{2}(\vec{w}) s_{2}^{*}(\vec{w})\right\rangle}}
$$

where $\langle\cdot\rangle$ denotes the expectation operator, ${ }^{*}$ is the complex conjugate, and $\vec{w}$ is the polarization of the images used to form the coherence [29].
Neglecting temporal decorrelation and assuming sufficient compensation of system [30] and geometric [31] decorrelation contributions, let $\gamma_{z}$ represent the coherence from (2) dependent only upon the vertical distribution of scatterers. The coherence magnitude $\left|\gamma_{z}\right|$ is postulated to be a combination of volume scattering with complex coherence $\gamma_{\text {vol }}$ and a surface scattering component whose relative strength is given by ground-tovolume scattering ratio $m$ [24], i.e.,

$$
\left|\gamma_{z}(\vec{w})\right|=\left|e^{j \phi_{0}}\left(\frac{\gamma_{\mathrm{vol}}\left(\kappa_{e}(\vec{w})\right)+m(\vec{w})}{1+m(\vec{w})}\right)\right|
$$

where $e^{j \phi_{0}}$ is the topographic phase factor, and $j$ is the imaginary unit, and it is assumed that surface and volume scattering mechanisms are uncorrelated. The surface scattering component is presumed to consist of contributions from sastrugi at the air-snow interface and from scattering at the snow-firn interface. Due to an unknown snow depth, it is assumed that sastrugi and snow-firn interface contributions both lie at $z=0$ in (3) since winter accumulation is generally less than a few meters [32]. Note that this is a simplification of Fig. 1 such that the sastrugi (air-snow) and snow-firn interfaces are colocated. Since dry snow is highly transparent at L- and P-band wavelengths, volume scattering from the winter snowpack is considered insignificant. The topographic phase $\phi_{0}$ is eliminated as an unknown by taking the magnitude in (3). Assuming an infinite uniform volume, $\gamma_{\mathrm{vol}}$ can be represented by (see Appendix A [33]):

$$
\gamma_{\mathrm{vol}}=\frac{1}{1+\frac{j \cos \left(\theta_{r}\right) k_{z \mathrm{vol}}}{2 \kappa_{e}}}
$$

where $k_{z \mathrm{vol}}$ is the vertical wavenumber in the volume. Multiple scattering is neglected, and it is assumed that topographic variations within the averaging window are negligible, which is reasonable for the relatively flat ice caps and sheets examined here. A derivation of (4) and the expression for $k_{z \mathrm{vol}}$ are given in Appendix A.

Extinction can be determined by inverting (3) and (4) at each polarization and each pixel independently, i.e.,

$$
\kappa_{e}=\frac{\cos \left(\theta_{r}\right)\left|k_{z \mathrm{vol}}\right|}{2(1+m)} \sqrt{\frac{\left|\gamma_{z}\right|^{2}(1+m)^{2}-m^{2}}{1-\left|\gamma_{z}\right|^{2}}}
$$

where $m,\left|\gamma_{z}\right|$, and $\kappa_{e}$ are polarization dependent ( $\vec{w}$ dependences have been dropped in (5) for clarity). The absolute value of the vertical wavenumber in the volume $\left(\left|k_{z \mathrm{vol}}\right|\right)$ is taken to obtain a positive (and physically meaningful) extinction when selecting the positive value of the square root in (5). Note that (5) is difficult to analytically derive and was determined using the aid of Mathematica [34] software.

The coherence magnitude model in (3) was chosen because of its ability to describe variations in $\left|\gamma_{z}\right|$ as a function of $k_{z \mathrm{vol}}$ for experimental data at L-band over a wide range of baselines [35] while remaining simple enough to allow extinction inversion from a limited number of observables. However, as shown in [24] and [35], observed coherence phases are inconsistent with the model for $\gamma_{z}$ [see (3)]. Using the interferometric phase of corner reflectors on the snow surface (and snow depth measurements [35]) as a reference to derive the location of the snow-firn interface, it was shown that observed interferometric 
phase centers are deeper than would be expected assuming the infinite uniform volume from (4). In [24], a model accounting for firn densification with increasing depth was introduced to account for this effect leading to a depth-dependent extinction coefficient, although no physically realistic density-depth relation was found to explain the observed coherences.

Another possible reason for deeper interferometric phase centers is that surface scattering, parameterized by $m$ in (3), is not solely located at the snow-firn interface (with interferometric phase $e^{j \phi_{0}}$ ) but is rather distributed over a finite depth due to layering within the ice, which is discussed in Section III-B. Thus, the single $m$ in (3) could be replaced with a series of values, one for each layer, each with a unique phase determined by its depth. Deeper interferometric phases centers could also result from multiple scattering which leads to increased path lengths, from correlations between scattering mechanisms [assumed negligible in (3)] or from a combination of some or all of the aforementioned effects. The additional complexity of incorporating such effects into scattering models, however, often leads to underestimated inversion problems due to an increased number of parameters. Such problems can be unambiguously solved only under simplifying assumptions or with a priori information (requiring additional and detailed field measurements in harsh and remote polar locations) and can have constrained applicability. The influences of each of the aforementioned effects on the Pol-InSAR complex coherence have not been investigated in detail in the literature and are beyond the scope of this paper. Nevertheless, for a fixed extinction value, simulations of the influence of an additional scattering layer [see (15) in Section III-B] have revealed the interferometric phase to be more sensitive than the interferometric coherence to a violation of the single surface layer assumption.

Therefore, only coherence magnitudes are used, providing a single InSAR observable for each polarization. One observable is insufficient to invert the two unknowns $m$ and $\kappa_{e}$. To solve for extinction in this paper, $m$ is estimated independently of (3) using the polarimetric scattering signature, as discussed in Section II-B. An accurate modeling of the full observables (particularly polarimetric and interferometric phases) is not yet available and will perhaps require fully phase-coherent models, although the proposed model can explain some of the observed PolSAR and InSAR properties of the experimental data.

\section{B. Ground-to-Volume Scattering Ratio Model}

To determine the ground-to-volume scattering ratio $m$ in (3), surface and volume scattering components must be separated. To achieve this, a three-component polarimetric decomposition for glacier ice [10] is used, consisting of a ground component from the snow-firn interface (described by the first-order smallperturbation method (SPM) [19]), a random volume of dipoles (as in [36]), and an oriented sastrugi field (caused by windinduced features at the snow surface). Assuming all components are uncorrelated, the combined covariance matrix is a sum of the matrices for the individual mechanisms plus an additive noise contribution, i.e.,

$$
C_{\text {total }}=C_{g}+C_{v}+C_{s}+N
$$

where subscript $g$ is the ground (i.e., snow-firn interface), $v$ is the volume, $s$ is the sastrugi, and $\boldsymbol{N}$ is the diagonal additive noise matrix. Covariance matrices for each component are given in Appendix B.

Results from the polarimetric decomposition are used to separate power contributions from surface and volume scattering mechanisms for each polarization in the $H-V$ basis. Parameter $m$, which is the ground-to-volume scattering ratio, is defined to quantify the relative surface and volume contributions. $m$ is computed using the powers along the main diagonals of the modeled covariance matrices, i.e.,

$$
\begin{aligned}
& m_{H H}=\frac{C_{g 11}+C_{s 11}}{C_{v 11}} \\
& m_{H V}=\frac{C_{s 22}}{C_{v 22}} \\
& m_{V V}=\frac{C_{g 33}+C_{s 33}}{C_{v 33}} .
\end{aligned}
$$

Note that a ground contribution for $H V\left(C_{g 22}\right)$ is not included in (7) because the first-order SPM does not predict a cross-polarized component.

Previous characterizations of the relative surface and volume contributions for glaciers and ice sheets have relied on linear fits to data at multiple incidence angles from either time-separated acquisitions of the same areas [37], during which surface conditions could have changed, or from linear fits over large ( $>50 \mathrm{~km}$ ) swaths [20], thus assuming homogeneous test sites. In this paper, the polarimetric information of the SAR signal is exploited to estimate $m$ for each covariance matrix realization without presumption of a relationship with incidence angle.

\section{ESTIMATION ACCURACY}

In this section, the estimation accuracy of two parameters, i.e., the ground-to-volume scattering ratio and the extinction coefficient, are evaluated using the models from Section II.

\section{A. Ground-to-Volume Scattering Ratio Estimation Accuracy}

From (7), the relationship between an uncertainty in the ground, sastrugi, and volume powers and the uncertainty in the estimated ground-to-volume scattering ratio can be evaluated by taking partial derivatives with respect to each parameter in $m=\left(P_{g}+P_{s}\right) / P_{v}$, i.e.,

$$
\Delta m=\frac{1}{\sqrt{N_{\mathrm{eff}}}} \sqrt{\left(\frac{\partial m}{\partial P_{g}} \Delta P_{g}\right)^{2}+\left(\frac{\partial m}{\partial P_{s}} \Delta P_{s}\right)^{2}+\left(\frac{\partial m}{\partial P_{v}} \Delta P_{v}\right)^{2}}
$$

where $\Delta m$ represents the uncertainty in $m$ caused by uncertainties in the polarization-dependent input powers $P_{g}(\vec{w}), P_{s}(\vec{w})$, and $P_{v}(\vec{w})$, and it is assumed that correlations between powers are negligible. A further averaging of input powers by $N_{\text {eff }}$ effective number of covariance looks is included, which has the effect of reducing the overall uncertainty by $\sqrt{N_{\text {eff }}}$. Evaluating (8) and assuming identical uncertainties in the powers for simplicity (i.e., $\Delta P=\Delta P_{g}=\Delta P_{s}=\Delta P_{v}$ ) yields

$$
\Delta m_{\mathrm{co}-\mathrm{pol}}=\frac{\sqrt{\left(P_{s}+P_{g}\right)^{2}+2 P_{v}^{2}}}{P_{v}^{2} \sqrt{N_{\mathrm{eff}}}} \Delta P .
$$




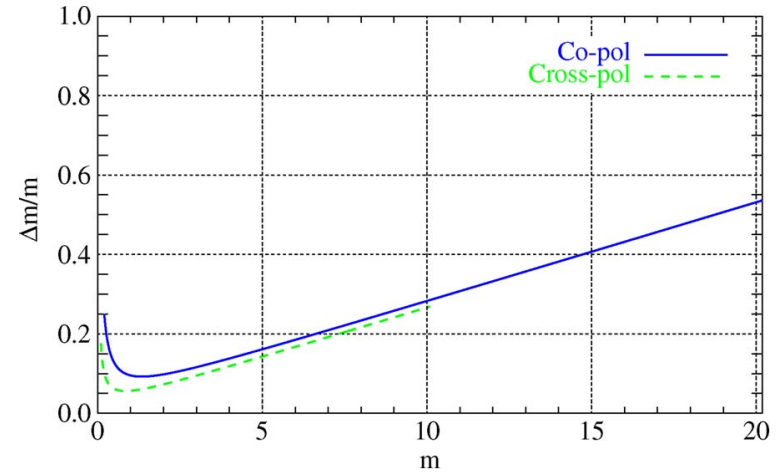

Fig. 2. Relative error in the ground-to-volume scattering ratio $(\Delta m / m)$ versus $m$ evaluated using (9) and (10) for $\Delta P=3 \%$ of the total power and nine effective covariance looks.

For the $H V$ component in which $P_{g}$ is set to zero, the error in $m$ will be

$$
\Delta m_{\mathrm{cross}-\mathrm{pol}}=\frac{\sqrt{P_{s}^{2}+P_{v}^{2}}}{P_{v}^{2} \sqrt{N_{\mathrm{eff}}}} \Delta P .
$$

The relative error $\Delta m / m$ is plotted in Fig. 2 as a function of $m$. For the simulation results presented in Fig. 2, $\Delta P, P_{s}$, $P_{g}$, and $P_{v}$ were determined using the following assumptions. The uncertainty in input powers $\Delta P$ was set to $3 \%$ of the total power. This value was obtained from the polarimetric decomposition of simulated data generated using the threecomponent model from Section II-B and Appendix B and assuming fully developed speckle. Covariance matrices with 100 independent looks were used in the polarimetric decomposition, and $512 \times 512$ independent realizations were generated. To further improve uncertainties in $m$, power values are averaged over a $20 \times 20$ window (corresponding to only $\sim 9$ effective covariance looks), although this comes at the cost of a reduced spatial resolution. The model parameters were chosen assuming realistic values of snow and firn dielectric constants [see (Appendix B)], surface roughness parameters from the literature [21], [38], reflection-symmetric sastrugi, and volume scattering power coefficients estimated from $H V$ magnitudes of the experimental data. Further details on these simulations are available in [10].

For simplicity, the polarizations are assumed to have equal sastrugi powers in Fig. 2, i.e., $P_{s H H}=P_{s V V}=P_{s H V}$ and the co-pols to have equal ground powers $P_{g H H}=P_{g V V}$. The sastrugi powers, in particular, may change as a function of sastrugi orientation and distribution with respect to the line of flight, but here, randomly distributed sastrugi are assumed. For a conservative estimate of errors, equal powers have been assumed for sastrugi and ground scattering components, i.e., $P_{s}=P_{g}$. Lower sastrugi powers than ground powers are generally expected, however (see [10]), which will lower overall uncertainties. Volume powers $P_{v}$ were varied to give a variation in $m$ in Fig. 2. In reality sastrugi and ground powers are polarization and test site dependent and thus Fig. 2 provides only a rough estimate of estimation accuracies. Because no ground power component is present in the cross-pol, $m$ values are smaller than for the co-pols.
Excluding values with $m<1$, it is shown in Fig. 2 that the relative error in $m$ nearly linearly increases with increasing $m$. For $m \geq 40$, uncertainties exceed $100 \%$. At long wavelengths for which volume scattering from snow and ice grains is expected to be relatively small, and in areas with limited volume scattering due to a lack of melt structures, this implies high values and, thus, poor characterization of $m$. It is perhaps not surprising that it is difficult to extract ice volume parameters if the SAR signal is dominated by the surface response. These results indicate that ground-to-volume scattering ratios will be best estimated for scenarios with a balance of both surface and volume returns (i.e., for $m \simeq 1$ ). Further improvements in parameter estimation could be achieved by increasing the number of looks used for ground-to-volume scattering ratio estimation; this is accompanied by a loss in spatial resolution, which may be acceptable over homogeneous ice sheets, although fine details regarding firn structure may be lost and heterogeneity within the averaging window may violate model assumptions.

\section{B. Extinction Estimation Accuracy}

A similar analysis is used to evaluate the sensitivity of extinctions to errors in the input parameter $m$ and to estimation errors in the coherence magnitude $\left|\gamma_{z}\right|$. The extinction uncertainty $\Delta \kappa_{e}$ is evaluated by taking partial derivatives of (5) with respect to $m$ and $\left|\gamma_{z}\right|$, i.e.,

$$
\Delta \kappa_{e}=\sqrt{\left(\frac{\partial \kappa_{e}}{\partial m} \Delta m\right)^{2}+\left(\frac{\partial \kappa_{e}}{\partial\left|\gamma_{z}\right|} \Delta\left|\gamma_{z}\right|\right)^{2}}
$$

where

$$
\begin{aligned}
\frac{\partial \kappa_{e}}{\partial m}= & \frac{m\left|k_{z \mathrm{vol}}\right| \cos \left(\theta_{r}\right)}{2(1+m)^{2}\left(\left|\gamma_{z}\right|^{2}-1\right)} \\
& \times \sqrt{\frac{1-\left|\gamma_{z}\right|^{2}}{\left|\gamma_{z}\right|^{2}(1+m)^{2}-m^{2}}} \\
\frac{\partial \kappa_{e}}{\partial\left|\gamma_{z}\right|}= & \frac{\left|\gamma_{z}\right|\left|k_{z \mathrm{vol}}\right|(1+2 m) \cos \left(\theta_{r}\right)}{2(1+m)\left(\left|\gamma_{z}\right|^{2}-1\right)^{2}} \\
& \times \sqrt{\frac{1-\left|\gamma_{z}\right|^{2}}{\left|\gamma_{z}\right|^{2}(1+m)^{2}-m^{2}}} .
\end{aligned}
$$

It should be noted that, when the error in $m$ or $\left|\gamma_{z}\right|$ is too large or when the relation between them is not described by the model in (3), it is possible that the factor under the square root in (5), (12) and (13) becomes negative for which no solution is defined.

The uncertainty in the ground-to-volume scattering ratio $\Delta m$ was derived in Section III-A, and the relative error $\Delta m / m$ is approximated as a linear fit to the co-pol results in Fig. 2. In [39], the Cramér-Rao lower bound on the variance of the interferometric coherence magnitude as a function of the effective number of looks $L_{\text {eff }}$ was computed, corresponding to a standard deviation $\Delta\left|\gamma_{z}\right|$ of

$$
\Delta\left|\gamma_{z}\right|=\frac{1-\left|\gamma_{z}\right|^{2}}{\sqrt{2 L_{\mathrm{eff}}}}
$$

In Fig. 3, uncertainties in the estimated extinction at L-band are plotted both as a function of ground-to-volume scattering ratio and horizontal baseline $(B)$ for incidence angles $\left(\theta_{\text {inc }}\right)$ 


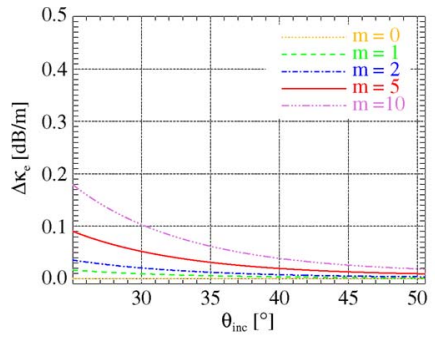

(a)

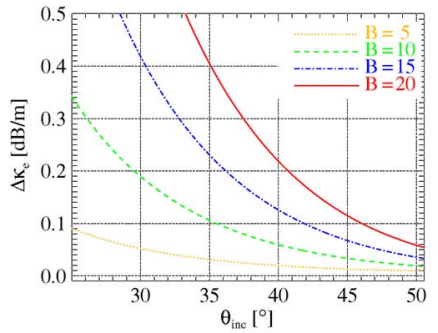

(c)

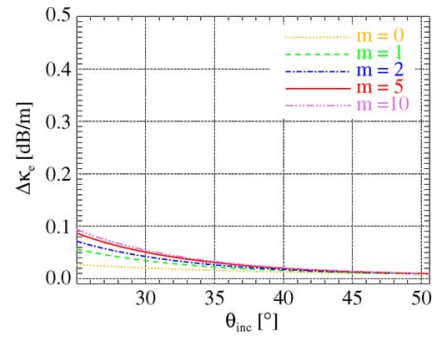

(b)

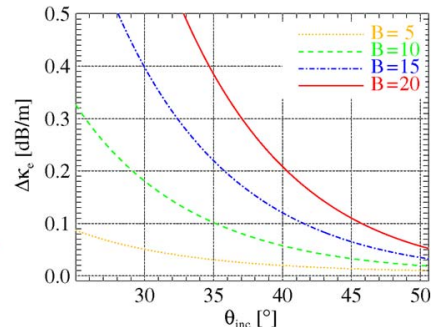

(d)
Fig. 3. Extinction coefficient uncertainty $\left(\Delta \kappa_{e}\right)$ at L-band versus incidence angle $\left(\theta_{\text {inc }}\right)$ as a function of (a) and (c) an uncertainty in $m$ and (b) and (d) an uncertainty in coherence magnitude. In (a) and (b), the horizontal baseline is fixed to $5 \mathrm{~m}$ and $m$ is varied from 0 to 10 . In (c) and (d) $m=5$ is fixed and the baseline is varied from 5 to $20 \mathrm{~m}$. (a) $\Delta \kappa_{e}$ due to $\Delta m$ for $B=5 \mathrm{~m}$. (b) $\Delta \kappa_{e}$ due to $\Delta\left|\gamma_{z}\right|$ for $B=5 \mathrm{~m}$. (c) $\Delta \kappa_{e}$ due to $\Delta m$ for $m=5$. (d) $\Delta \kappa_{e}$ due to $\Delta\left|\gamma_{z}\right|$ for $m=5$.

ranging from $25^{\circ}$ to $50^{\circ}$. The relation between effective baseline $B_{\perp}$ and wavenumbers $k_{z}$ and $k_{z \mathrm{vol}}$ is given in Section II-A and Appendix A, and the coherence magnitude is computed using (3). Since the baselines flown for the experimental data (Section IV) have larger baseline-to-wavelength ratios for L-band than for P-band, L-band is more sensitive to baselinedependent effects, and for conciseness, plots are shown only for this frequency. Simulations were carried out for a fixed number of looks $L_{\text {eff }}=100$ and for a fixed extinction $\kappa_{e}=0.1 \mathrm{~dB} / \mathrm{m}$, in accordance with inverted L-band extinction values from the Austfonna firn zone in [40]. Ground-to-volume scattering ratios are varied between 0 and 10, and L-band baselines emulating the experimental airborne data of between 5 and $20 \mathrm{~m}$ are used, where, for $B=5 \mathrm{~m}, k_{z}$ ranges from 0.03 to 0.11 with a minimum in the far range and, for $B=20 \mathrm{~m}$, the vertical wavenumber varies from $0.12<k_{z}<0.45$. A flight altitude of $4.7 \mathrm{~km}$ is assumed for all cases, which is consistent with the experimental data.

It is shown in Fig. 3 that errors in extinction are greatest in the near range since, in the near range, the effective baselines and thus $k_{z}$ are larger, with increased sensitivity to errors in the input parameters. At longer baselines, the coherence magnitude decreases [evaluation of (4)] and its variance increases in accordance with (14). Higher values of $m$ increase coherence magnitude [see (3)], although the reduction in $\Delta\left|\gamma_{z}\right|$ in (14) is offset by an increase in error $\Delta m$ according to Fig. 2 . The best estimates of $\kappa_{e}$ are obtained at shallow incidence angles (with low $k_{z}$ ) and for small $m$.

Because of the poor performance at larger baselines $\left(k_{z}>\right.$ 0.1 ), a wavenumber threshold is introduced to exclude radar geometry configurations for which uncertainties in $\kappa_{e}$ are greatly increased. In Fig. 4, the total combined uncertainty in $\Delta \kappa_{e}$ due to both $\Delta m$ and $\Delta\left|\gamma_{z}\right|$ is shown as a function of ground-to-

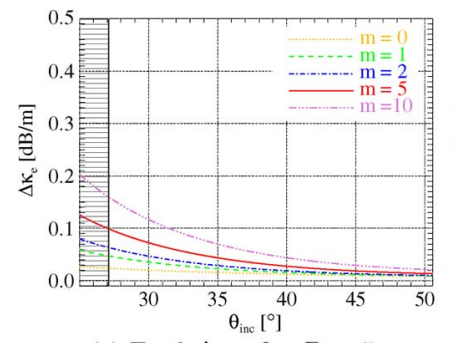

(a) Total $\Delta \kappa_{e}$ for $B=5 \mathrm{~m}$

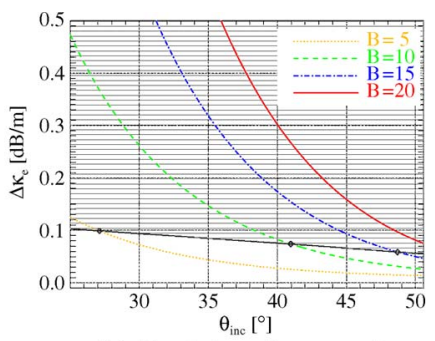

(b) Total $\Delta \kappa_{e}$ for $m=5$
Fig. 4. Extinction coefficient uncertainty $\left(\Delta \kappa_{e}\right)$ versus incidence angle $\left(\theta_{\text {inc }}\right)$ as a function of (a) ground-to-volume scattering ratio and (b) baseline. The hatched areas represents solution regions for which vertical wavenumber $k_{z}>0.1$.

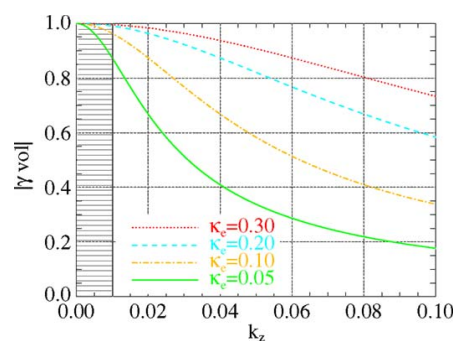

Fig. 5. Coherence magnitudes versus $k_{z}$ for a volume with $0.05 \leq \kappa_{e} \leq$ $0.3 \mathrm{~dB} / \mathrm{m}$ and no surface contribution $(m=0)$. The hatched area represents the solution region for which vertical wavenumber $k_{z}<0.01$.

volume scattering ratio and baseline, where the hatched area corresponds to regions where $k_{z}>0.1$, which are excluded due to their prohibitively high uncertainties. In Fig. 4, it is shown that an error of less than $0.1 \mathrm{~dB} / \mathrm{m}$ can be expected in $\kappa_{e}$ when $k_{z} \leq 0.1$ and $m \leq 5$. However, without a priori knowledge of $m$, it is difficult to optimize baseline $B$. Multiple baselines offer additional estimates of $\kappa_{e}$, which may be combined for a more robust extinction estimation. In mid range to far range, sensitivity to errors in the input parameters is lower, and expected extinction accuracies improve to $\sim 0.05 \mathrm{~dB} / \mathrm{m}$ for a single baseline (see Fig. 4) and $0.025 \mathrm{~dB} / \mathrm{m}$ for four baselines.

It would appear from Fig. 4(b) that the smallest possible baselines should be used for extinction inversion. However, as $k_{z}$ approaches zero, the coherence magnitude no longer displays sensitivity to extinction. This is demonstrated in Fig. 5, which plots the relationship between $k_{z}$ and coherence magnitude $\left|\gamma_{\text {vol }}\right|$ for a varying extinction coefficient $(0.05 \leq$ $\left.\kappa_{e} \leq 0.3 \mathrm{~dB} / \mathrm{m}\right)$. The hatched area corresponds to regions where $k_{z}<0.01$, which are excluded due to an insensitivity in coherence magnitude to changes in extinction. Small uncompensated decorrelation sources such as from temporal decorrelation or coregistration errors result in a large error in inverted extinctions at very small baselines. Accordingly, a minimum $k_{z}$ threshold of 0.01 is used in this paper to limit errors in extinction inversion.

An uncertainty in extinction may also arise from uncertainties in the dielectric constant $\varepsilon_{r}$, which was assumed known for the computation of $k_{z \mathrm{vol}}$ [see (17)]. However, assuming variations of \pm 0.17 in $\varepsilon_{r}$ (derived from density variations of $\pm 50 \mathrm{~kg} / \mathrm{m}^{3}$ and the density-permittivity relation in [41]), extinction uncertainties are minimal (less than $0.02 \mathrm{~dB} / \mathrm{m}$ for $m \geq 1)$. 
Additional uncertainties are possible due to incorrect model assumptions. In order to model the coherence with a limited number of parameters, several simplifications have been made including the assumption of colocated sastrugi and ground returns at the snow-firn interface. It is plausible that the "surface" response modeled in (3) is, in fact, not a single snow-firn interface at depth $z=0$, rather the return from multiple stratified layers in the upper few meters, where the $i$ th layer with groundto-volume scattering ratio $m_{i}$ is located at depth $z_{i}$. In the case of a multiple-layer model, an additional pair of unknowns $\left\{m_{i}, z_{i}\right\}$ is introduced for each extra layer resulting in effective coherence magnitude, i.e.,

$$
\left|\gamma_{z}\right|=\left|e^{j \phi_{0}}\left(\frac{\gamma_{\mathrm{vol}}+\sum_{i=0}^{N-1} m_{i} e^{j k_{z \mathrm{vol}} z_{i}}}{1+\sum_{i=0}^{N-1} m_{i}}\right)\right|
$$

where $N$ represents the total number of layers including the snow-firn interface. For $N \geq 2$, (15) is no longer invertible with a single interferometric baseline. However, even a twolayer model is sufficient to better explain experimental observables; the two ground contributions are no longer in phase, such that the sum in the nominator of (15) yields a reduced combined $m$ and, thus, deeper interferometric phase centers (particularly at larger baselines), and yields slightly reduced coherence magnitudes compared with (3) for $z_{i}$ on the order of a few meters. The greatest sensitivity to an uncertainty in the location of the ground returns is for large baselines (i.e., large vertical wavenumbers $k_{z}$ ), offering further support for the use of a wavenumber threshold.

\section{EXPERIMENTAL DATA}

\section{A. Test Sites}

The test sites are located on the Austfonna ice cap, situated on the island of Nordaustlandet in northeastern Svalbard, Norway $\left(79.7^{\circ} \mathrm{N}, 24.0^{\circ} \mathrm{E}\right)$. Two sites were overflown: one in the firn zone near the summit of the ice cap (referred to as "Summit") and one in the superimposed ice (SI) zone near the Etonbreen outlet glacier ("Eton"). Both sites lie in the accumulation zone of the ice cap, such that there is a net mass balance gain at the end of the summer, although the sites have differing near-surface structure due to variation in summer melt.

In the firn zone, meltwater percolates downward before refreezing into horizontally distributed ice layers or ice lenses and vertically distributed ice pipes, which can appear extremely bright in SAR imagery [6]. In the SI zone, meltwater freezes onto the cold glacier ice at the base of the snowpack, forming more homogeneous SI. Topography is very gentle with surface slopes of less than a few degrees at both sites.

\section{B. SAR Data}

The airborne SAR data were acquired as part of the IceSAR campaign in spring 2007, which was a joint project between the Microwaves and Radar Institute of the DLR and the Alfred Wegener Institute, and was supported by the European Space Agency (ESA). Repeat-pass fully polarized L-band $(1.3 \mathrm{GHz})$ and P-band (350 MHz) data were collected using DLR's
E-SAR system. Repeat passes were flown at nominal baselines of 5-20 m at L-band and $10-40 \mathrm{~m}$ at P-band at an aircraft altitude of $4.7 \mathrm{~km}$. For certain acquisitions, passes were flown from both north and south sides of the test sites, with four passes per side. Unless otherwise noted, results shown are from the north-flying passes. The incidence angle varies from $25^{\circ}$ to $50^{\circ}$, and the data have a resolution of $2.1 \mathrm{~m} \times 1.0 \mathrm{~m}$ in slant range and azimuth, respectively. Vertical wavenumbers varied from $0.001<k_{z}<0.6$ at L-band and $0.001<k_{z}<0.3$ at P-band, varying for each baseline across-track due to a change in the incidence angle and in azimuth due to nonuniform tracks. Short temporal baselines of a maximum of $1 \mathrm{~h}$ were used to generate interferometric pairs. Initial Pol-InSAR processing steps have been carried out including InSAR flatearth phase removal and isolation of $\gamma_{z}$ through the estimation of range spectral decorrelation and signal-to-noise ratio (SNR) components. For Etonbreen P-band, where the SNR (estimated using the decorrelation of the cross-pol channels [42]) fell below $20 \mathrm{~dB}$, an additive noise correction was applied prior to polarimetric decomposition [10].

Fig. 6 displays composite Pauli RGB images of the polarimetric data. The Summit L-band image [see Fig. 6(a)] is relatively homogeneous, while P-band [see Fig. 6(b)], with deeper penetration depths, reveals the presence of multiple ice features. For the Etonbreen test site, both L-band and P-band [see Fig. 6(c) and (d)] show similar features, and the scene is much more inhomogeneous compared with Summit.

\section{Ground Measurements}

Since 2004, the University of Oslo and the Norwegian Polar Institute have carried out annual spring field campaigns on Austfonna. The measurements include GPR data in order to map snow depth and snow distribution, where results from the 2005 campaign were presented in [43] and those from the 2007 campaign in [32]. The 2007 campaign included meteorological measurements, snow stratigraphy, and GPR profiling, which were carried out during a two-week period spanning the end of April and the beginning of May prior to spring melt. The GPR data were collected using a commercial impulse radar system (RAMAC, Malå GeoScience) operating at a center frequency of $800 \mathrm{MHz}$, which lies between the L-band and P-band SAR frequencies. GPR amplitude profiles overlapping the SAR test sites (where profile locations are given in Fig. 6) versus twoway travel time are shown in Fig. 7. For visualization purposes, an exponential gain function has been applied to enhance layers at depth whose amplitudes are reduced due to attenuation and spherical spreading loss of the signal. The first (top) reflection in the GPR profiles is from the winter snow layer upon which the snowmobile is driving. The next strong reflection [particularly visible at $\sim 20 \mathrm{~ns}$ in Fig. 7(b)] is from the snow-firn interface, which constitutes the "ground" response in the PolInSAR model. Greater volume scatter is seen in the firn zone (Summit) than in the SI zone (Etonbreen) due to differences in near-surface melt features. The comparison of the GPR and SAR data is addressed in Section VI. A more thorough description of all available glaciological data for this test site is given in [16]. 


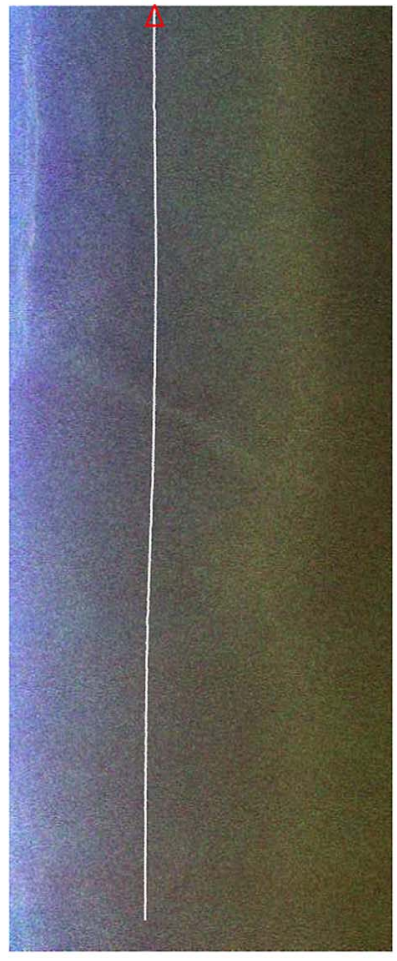

(a) Summit, L-band

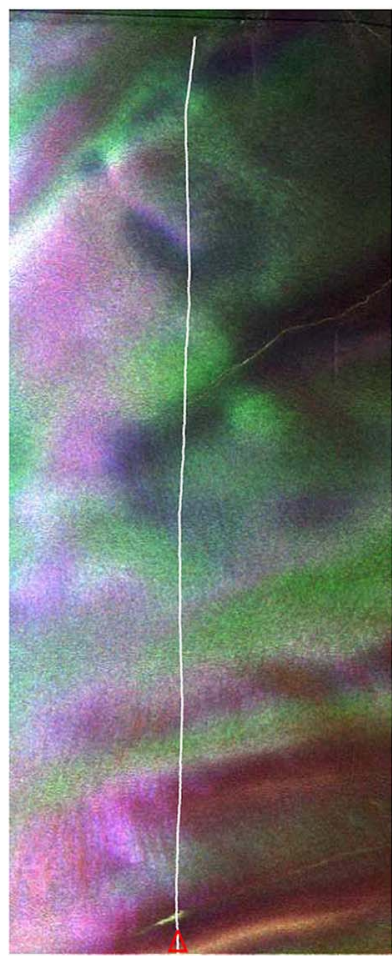

(c) Eton, L-band

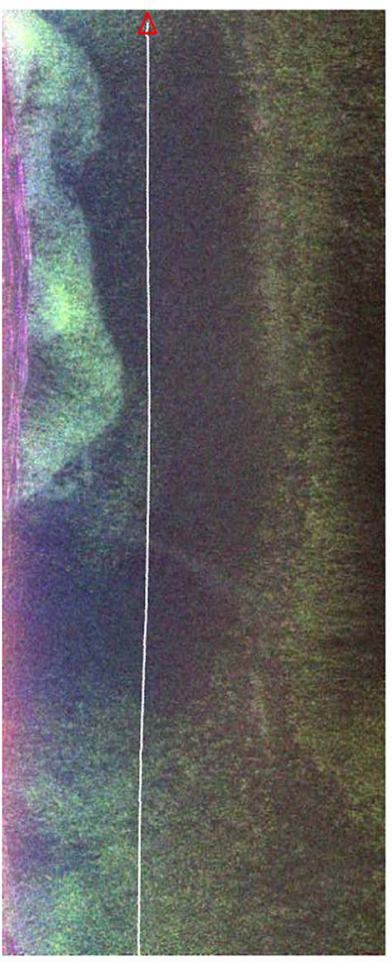

(b) Summit, P-band

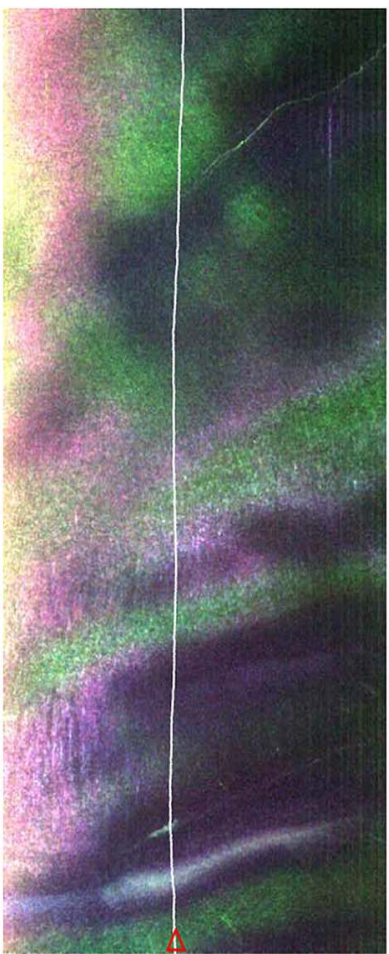

(d) Eton, P-band

Fig. 6. Pauli RGB decomposition of PolSAR data in slant-range geometry of the Austfonna ice cap. Flight (azimuth) direction is from bottom to top, and range direction is from left to right. L- and P-band images represent approximately the same area (each $\sim 3.5 \mathrm{~km}$ in ground range and $\sim 10 \mathrm{~km}$ in azimuth). The location of GPR profiles are shown in white, where the red triangle indicates the start position of the profile.

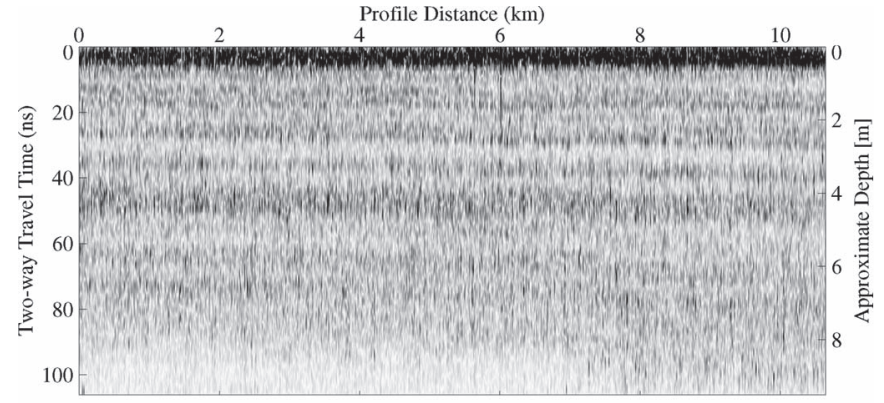

(a)

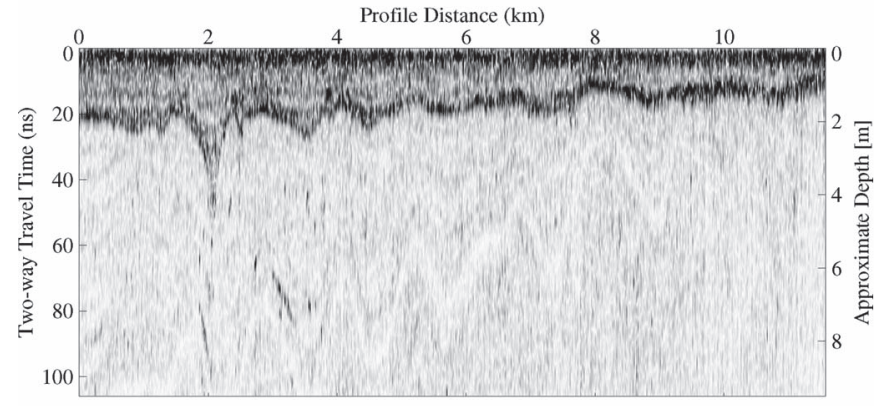

(b)

Fig. 7. GPR profiles overlapping the SAR test sites. Left-hand vertical scale is two-way traveltime in nanoseconds, and right-hand scale is approximate depth below the surface assuming a constant density of $800 \mathrm{~kg} / \mathrm{m}^{3}$, corresponding to a wave velocity of $179 \mathrm{~m} / \mu$ s. Layering at depth has been visually enhanced using an exponential gain with depth. (a) Summit. (b) Etonbreen.

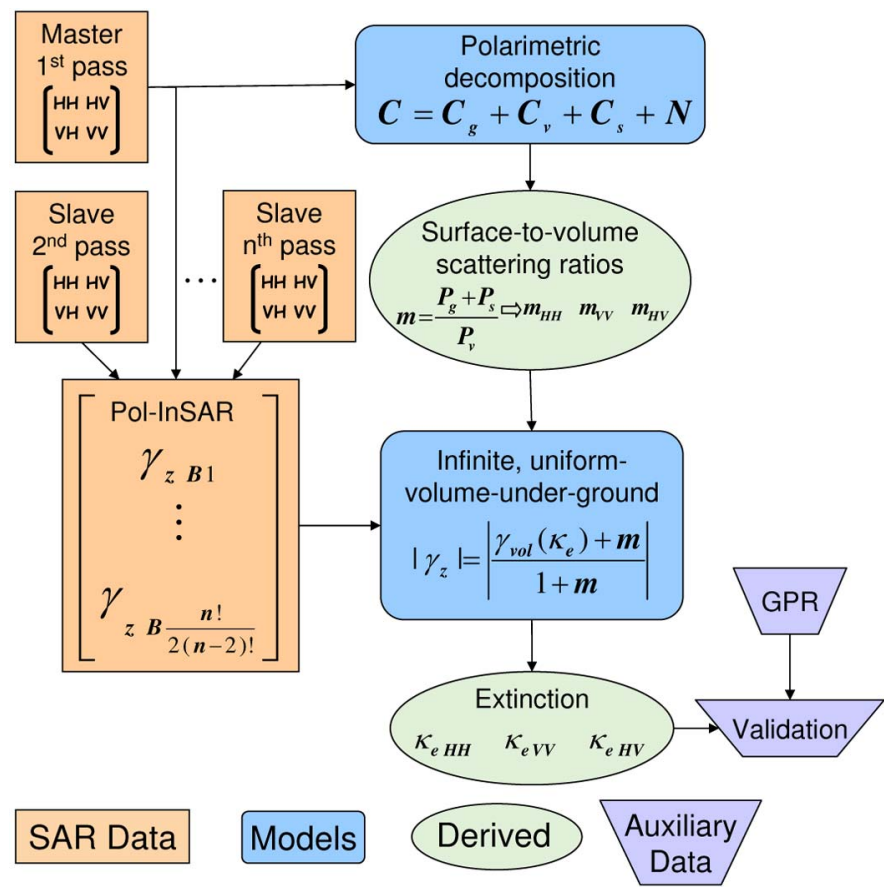

Fig. 8. Block diagram for extinction inversion.

\section{INVERSION RESULTS}

Polarimetric decomposition, as described in Section II-B, was applied to the experimental data. Ground-to-volume scattering ratios estimated from the combined surface over volume powers from (7) were used in combination with Pol-InSAR coherences and the infinite uniform-volume-under-ground model for the determination of the ice extinction coefficient using (5). A block diagram for extinction estimation is given in Fig. 8, 


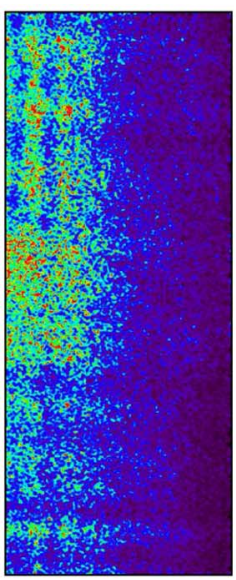

(a) L-VV

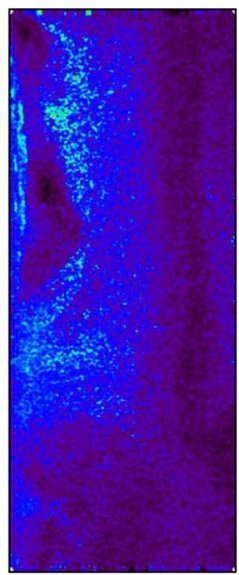

(d) P-VV

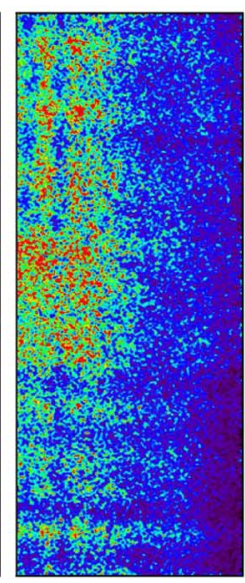

(b) $\mathrm{L}-\mathrm{HH}$

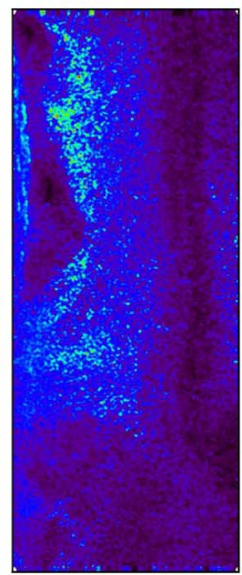

(e) $\mathrm{P}-\mathrm{HH}$

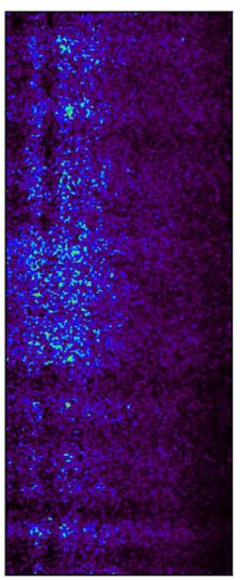

(c) L-HV

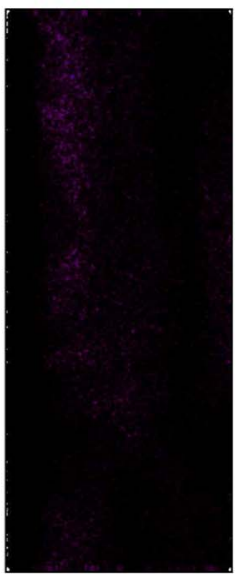

(f) P-HV

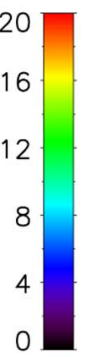

20
16
12
8
4
0

Fig. 9. Ground-to-volume scattering ratios for L-band and P-band, Summit.

which shows the separation between input data, models, derived results, and auxiliary data. Detailed decomposition results have been presented in [10], and thus, the focus in this paper is on the ground-to-volume scattering ratios and extinctions. Important results from [10] include an observed decrease in surface power with increasing incidence angle, which is expected from scattering theory [44]. Also, relative volume contributions were higher for the Summit than for the Etonbreen test site. This is expected as Summit is in the firn zone with many high-backscatter ice inclusions, whereas Etonbreen has fewer volume scatterers on the order of the wavelength. Observed sastrugi scattering was stronger at L-band than at P-band, which is further discussed in Section V-A.

\section{A. Ground-to-Volume Scattering Ratios}

Ground-to-volume scattering ratios are filtered to remove values of $m>40$, which are characterized by high uncertainties (see discussion in Section III-A). Results for Summit and Etonbreen test sites are presented in Figs. 9 and 10, respectively, where noninvertible pixels are colored white.

Looking at the overall trends, the homogeneous Summit L-band data and, to a lesser extent, the Summit P-band data show a decreasing trend in $m$ with increasing incidence angle, which is consistent with the SPM theory for a homogeneous

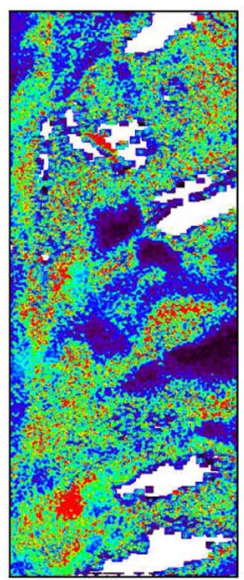

(a) L-VV

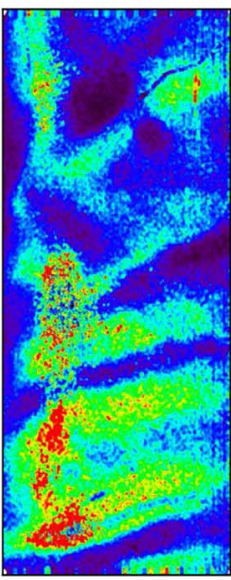

(d) P-VV

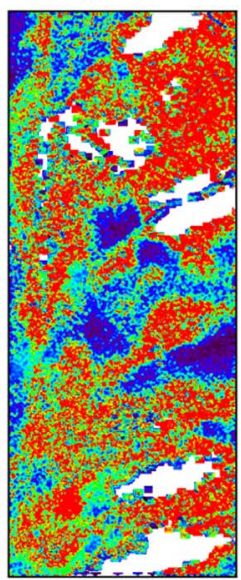

(b) $\mathrm{L}-\mathrm{HH}$

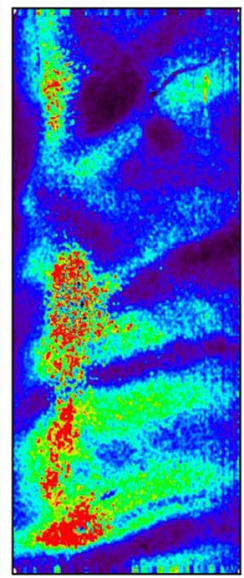

(e) $\mathrm{P}-\mathrm{HH}$

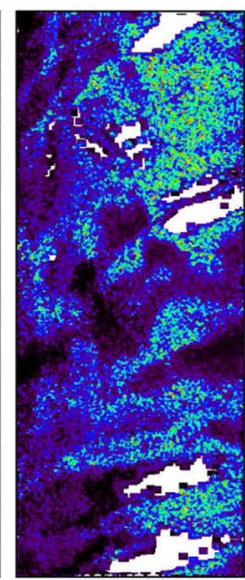

(c) L-HV

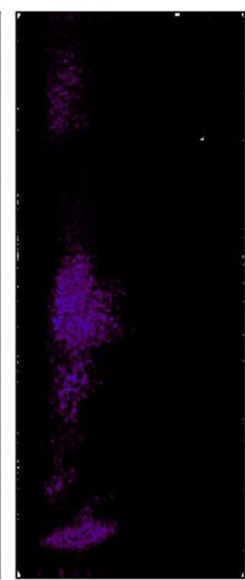

(f) $\mathrm{P}-\mathrm{HV}$
Fig. 10. Ground-to-volume scattering ratios for L-band and P-band, Etonbreen

surface. Etonbreen is more heterogeneous such that local variations in surface roughness and structure play a more dominant role than the incidence angle in determining $m$. Sastrugi scattering is expected to be much stronger at L-band than at the P-band at both test sites [10], leading to larger $m$ values at L-band. Perhaps, continuous sastrugi segments are more prevalent at L-band as the wavelength $(0.23 \mathrm{~m})$ is nearly four times smaller than that at P-band $(0.86 \mathrm{~m})$. The sastrugi have larger $H H$ than $V V$ backscatter due to sastrugi orientations roughly parallel to the horizontal polarization axis, leading to $m_{H H}>$ $m_{V V}$ at L-band. Ground-to-volume scattering ratios are also larger at Etonbreen than at Summit, which is expected due to the lack of large melt structures and, thus, less volume scattering in the SI zone of Etonbreen.

\section{B. Extinctions}

A spatial averaging window of 100 effective looks was used to compute interferometric coherences, corresponding to an approximately square window of $20 \mathrm{~m} \times 20 \mathrm{~m}$ in ground range. Results from multiple baselines are combined by first applying a mask of $0.01<k_{z}<0.1$ (see Section III-B) and are then averaged from the remaining valid baselines on a pixel-by-pixel basis. The four passes from each side of the test sites have 


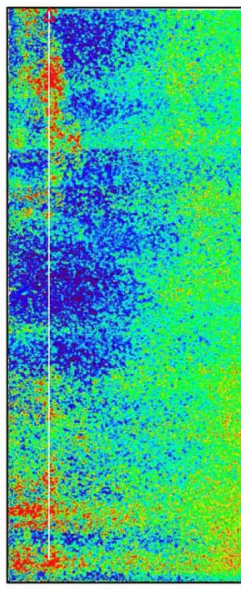

(a) $\mathrm{L}-\kappa_{e} \mathrm{VV}$

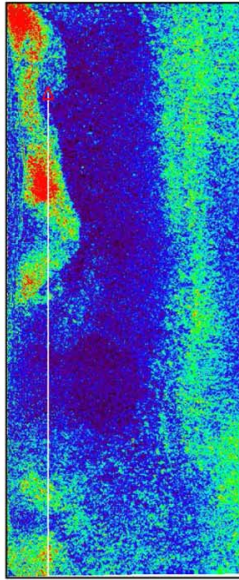

(d) $\mathrm{P}-\kappa_{e} \mathrm{VV}$

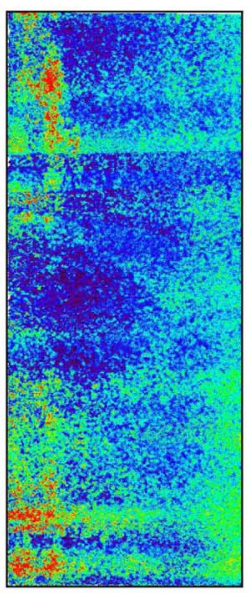

(b) $\mathrm{L}-\kappa_{e} \mathrm{HH}$

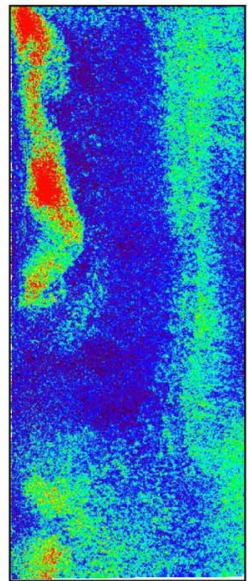

(e) $\mathrm{P}-\kappa_{e} \mathrm{HH}$

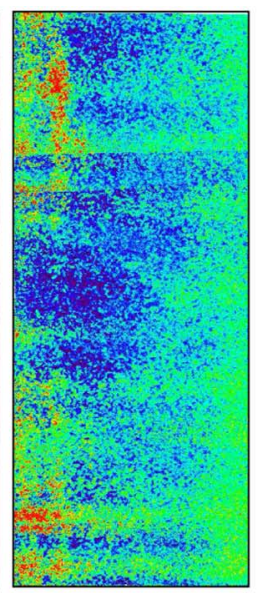

(c) $\mathrm{L}-\kappa_{e} \mathrm{HV}$

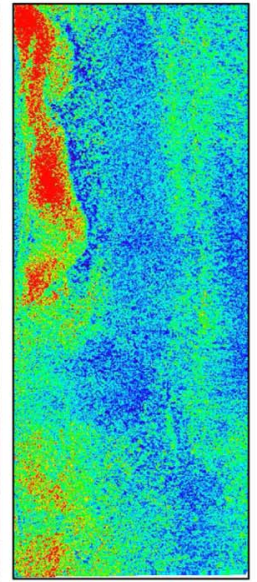

(f) $\mathrm{P}-\kappa_{e} \mathrm{HV}$

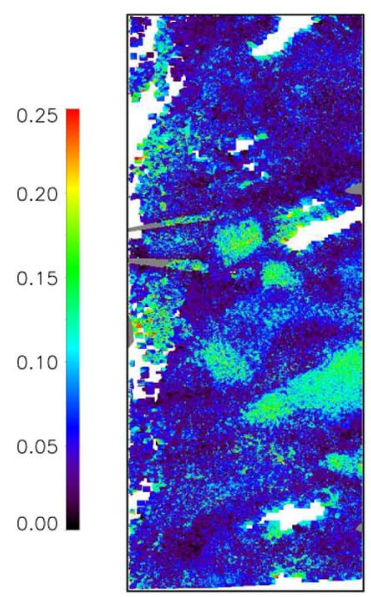

(a) $\mathrm{L}-\kappa_{e} \mathrm{VV}$

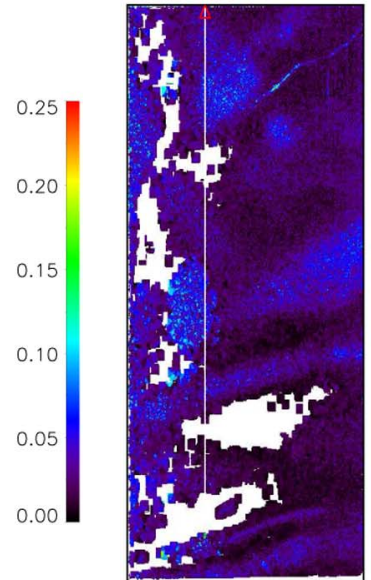

(d) $\mathrm{P}-\kappa_{e} \mathrm{VV}$

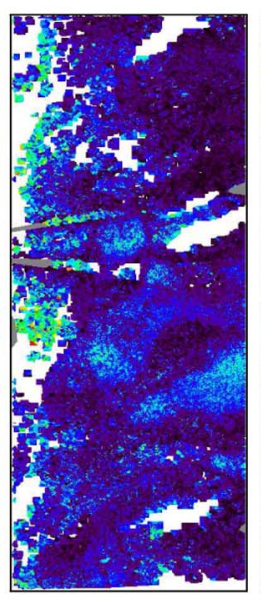

(b) $\mathrm{L}-\kappa_{e} \mathrm{HH}$

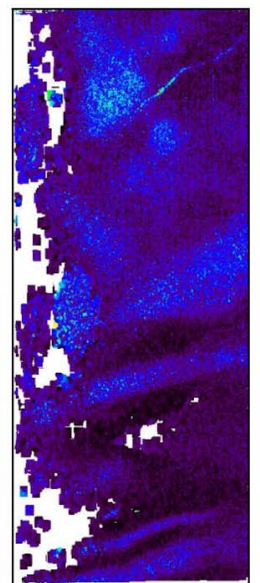

(e) $\mathrm{P}-\kappa_{e} \mathrm{HH}$

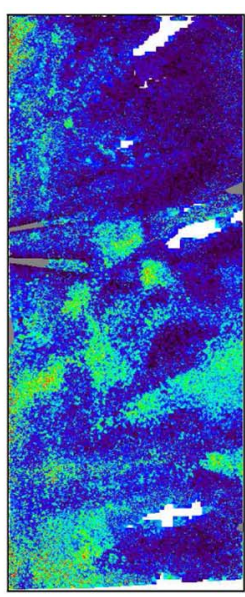

(c) L- $\kappa_{e} \mathrm{HV}$

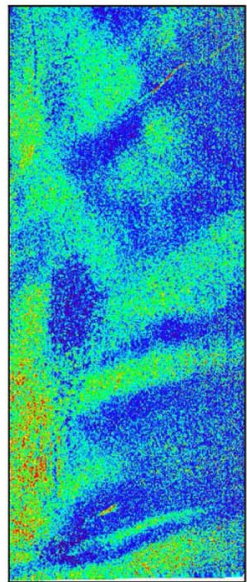

(f) $\mathrm{P}-\kappa_{e} \mathrm{HV}$

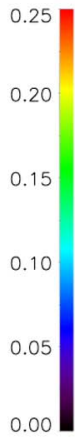

Fig. 11. Extinctions $\kappa_{e}$ (in decibels per meter) in slant-range geometry at Summit, North for L-band and P-band. Near range profiles for $V V$ in white (distinct from the GPR profiles in Fig. 6) are plotted in Fig. 14, where the red triangle indicates the start position of the profile. These profiles are used to compare extinctions from north- and south-flying passes in Fig. 14.

been combined to form six baselines for each side (although not all are independent). Because baseline-to-wavelength ratios are lower and $m$ values are smaller at P-band than at L-band, a greater number of baselines are able to provide valid extinction values at P-band. The application of the $k_{z}$ mask has the effect, however, of an inversion performance varying with range, with up to six baselines combined in far range and only one or two in near range.

Inverted volume extinction coefficients at $V V, H H$, and $H V$ polarizations for L-band and P-band are given in Fig. 11 for Summit and Fig. 12 for Etonbreen. As mentioned in Section III-B, large errors in estimated $m$ and $\left|\gamma_{z}\right|$ or pixels whose scattering is not described by the proposed model may yield a negative factor under the square root in (5) such that no solution can be found. Noninvertible pixels are colored white in Figs. 11 and 12 and pixels for which none of the baselines satisfied the $k_{z}$ criteria are shown in gray, which was only for small patches in Fig. 12(a)-(c). To examine trends with the incidence angle, extinctions over the entire image averaged through azimuth are shown in Fig. 13. Mean $\kappa_{e}$ averaged over each image is given in Table I to compare average levels between test
Fig. 12. Extinctions $\kappa_{e}$ (in decibels per meter) in slant-range geometry at Etonbreen, North for L-band and P-band, where noninvertible pixels are colored white. Near range profiles for $V V$ in white were described in the caption of Fig. 11. At Etonbreen, no south-flying L-band passes were available for comparison, and thus, no profile is plotted in (a).

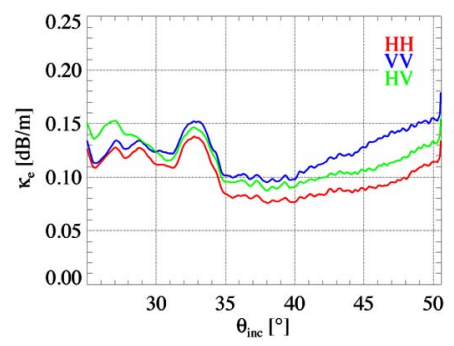

(a) Summit, L-band

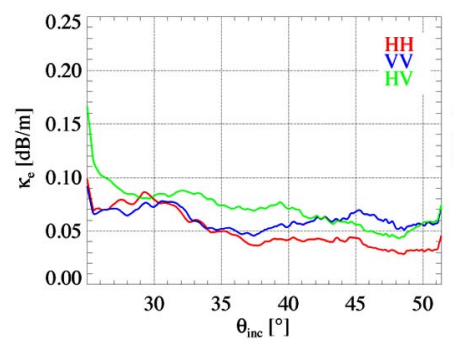

(c) Eton, L-band

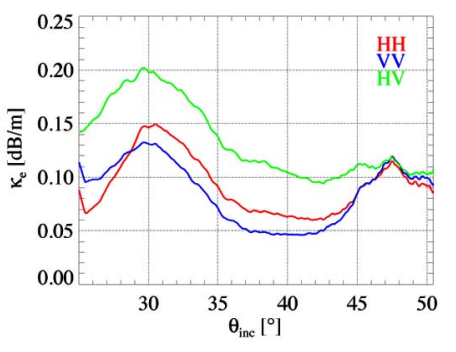

(b) Summit, P-band

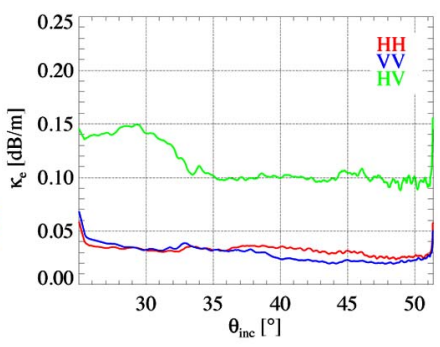

(d) Eton, P-band
Fig. 13. Extinction $\left(\kappa_{e}\right)$ versus incidence angle $\left(\theta_{\text {inc }}\right)$ averaged through azimuth. 
TABLE I

Mean and Standard DeViation of ICE Volume Extinctions AVERAGED ACROSS THE ENTIRE IMAGE

\begin{tabular}{lcccc}
\hline & \multicolumn{4}{c}{ mean $\kappa_{e} \pm \Delta \kappa_{e}[\mathbf{d B} / \mathbf{m}]$} \\
& & HH & VV & HV \\
\hline \multirow{3}{*}{ Summit } & $\mathrm{L}$ & $0.103 \pm 0.047$ & $0.131 \pm 0.053$ & $0.117 \pm 0.046$ \\
& $\mathrm{P}$ & $0.094 \pm 0.052$ & $0.091 \pm 0.054$ & $0.125 \pm 0.052$ \\
\multirow{4}{*}{ Eton } & & & & \\
& $\mathrm{L}$ & $0.047 \pm 0.030$ & $0.064 \pm 0.039$ & $0.079 \pm 0.062$ \\
& $\mathrm{P}$ & $0.037 \pm 0.020$ & $0.031 \pm 0.018$ & $0.106 \pm 0.059$ \\
\hline
\end{tabular}

TABLE II

Equivalent Penetration Depths Using Extinctions From TABLE I, ASSUMING A NADIR-LOOKING SySTEM

\begin{tabular}{lrrrr}
\hline & & \multicolumn{3}{c}{$d_{\text {pen }}[\mathbf{m}]$} \\
& & HH & VV & HV \\
\hline \multirow{2}{*}{ Summit } & L & 42.1 & 33.3 & 37.1 \\
& $\mathrm{P}$ & 46.1 & 48.0 & 34.8 \\
\multirow{2}{*}{ Eton } & $\mathrm{L}$ & 92.2 & 68.0 & 55.1 \\
& $\mathrm{P}$ & 116.0 & 138.3 & 40.8 \\
\hline
\end{tabular}

sites, frequencies, and polarizations. The equivalent penetration length (or penetration depth if $\theta_{\text {inc }}=0^{\circ}$ ) as defined in (1) is given in Table II.

Note that the standard deviations in Table I describe the variation in extinction over the entire scene, rather than the accuracy of the extinction measurement. Based on the simulations from Section III-B, inverted extinction estimates for a single realization in mid range to far range were predicted to have a standard deviation of $\sim 0.05 \mathrm{~dB} / \mathrm{m}$ for a single baseline and $0.025 \mathrm{~dB} / \mathrm{m}$ for four baselines when $\kappa_{e}=0.1 \mathrm{~dB} / \mathrm{m}$. For the experimental data, sample standard deviations were evaluated over the available baselines for each pixel. Averaged over the entire image and all polarizations, standard deviations were $\sim 0.05 \mathrm{~dB} / \mathrm{m}$ for Summit L-band and $0.04 \mathrm{~dB} / \mathrm{m}$ for Summit P-band, and $0.02 \mathrm{~dB} / \mathrm{m}$ for Etonbreen L-band and $0.01 \mathrm{~dB} / \mathrm{m}$ for P-band. Lower standard deviations at Etonbreen are attributed to lower $\kappa_{e}$ values at this test site (see Table I). When extinctions are combined for a four-baseline solution, these standard deviations are further reduced by a factor of two. Assuming unbiased $\kappa_{e}$ estimates and taking mean $\kappa_{e}$ values from Table I, accuracies $\left(\Delta \kappa_{e} / \kappa_{e}\right)$ of better than $25 \%$ are expected for a single realization, which are consistent with predicted accuracies from the simulations.

As expected, extinctions at Etonbreen are lower than those at Summit due to the lack of large-scale melt features to produce volume scattering. Some areas of Etonbreen could not be inverted because of very large $m$ values. In general, L-band shows slightly higher extinctions than P-band (see Table I), which is expected from scattering theory that predicts both absorption [45] and scattering [46] extinction coefficients in ice to increase with increasing frequency. Similar features can be recognized in the extinction maps at Summit between L-band and P-band such as areas of increased extinction in the irregularly shaped patches in the upper left and the lower left in Fig. 11(a)-(c) and (d)-(f) and a region of lower extinction (purple) in the center of the images. As Summit lies in the firn zone, the areas of higher extinction could correspond to the presence of enhanced melt features such as ice pipes and lenses. These features are better defined at P-band than at L-band, perhaps due to improved conditioning due to smaller $m$ and smaller $k_{z}$ values. L-band is also subject to greater inaccuracies in the vertical wavenumber from residual motion compensation errors due to its shorter wavelength, which are visible as streaking in the extinction through azimuth in Fig. 11(a)-(c).

Inverted extinctions for all three polarizations in the $H-V$ basis and their behavior as a function of incidence angle are examined in Fig. 13. Particular attention is given to the presence of differential extinction, i.e., polarization-dependent extinction, which implies an oriented volume. In [10], an oriented ice volume was suspected due to the presence of large $\left(-40^{\circ}\right.$ to $\left.90^{\circ}\right)$ copolar phase differences at L-band and P-band over the same test sites. However, to limit the number of unknowns and allow the inversion of the decomposition model, the volume was approximated as being random in the derivation of the groundto-volume scattering ratios. As extinctions are estimated for each polarization separately using (5), the assumption of a random volume (which should have polarization-independent extinctions) can be verified.

For Summit L-band, extinctions are approximately equal for all polarizations in near range to mid range [see Fig. 11(a)-(c) and 13(a)]. However, in far range, where the highest accuracies in $\kappa_{e}$ are expected due to the availability of multiple baselines within the desired $k_{z}$ range and less sensitivity to errors in the input parameters (see Fig. 4), there appears to be some differential extinction, suggesting the presence of a slightly oriented volume with a spread of $\sim 0.04 \mathrm{~dB} / \mathrm{m}$. For Summit P-band [see Fig. 11(d)-(f) and 13(b)], a different behavior is observed; across the entire incidence angle range, the co-pols have similar extinctions, although increases in the average extinction likely due to volumetric melt features are seen as two bumps at $\sim 30^{\circ}$ and $47^{\circ}$ in Fig. 13(b). The P-band cross-polarization shows elevated values in near range but very similar values to the copols in far range. The similarity of the co-pols and the nearly identical extinctions in far range, where $\kappa_{e}$ accuracies should be the highest, suggests that the random volume assumption was reasonable for P-band.

The incidence angle trend for $\kappa_{e H V}$ could indicate the presence of an uncompensated ground component in the crosspol. This is possible as the first-order SPM used in this paper for surface modeling predicts an $H V$ surface backscatter contribution of zero. Second-order terms from the SPM should perhaps be included for low-frequency surface scattering such as from P-band, particularly for cases in which the observed $H V$ return from the experimental data is very low (here, P-band $\sigma_{H V}^{0} \simeq-30 \mathrm{~dB}$ for Summit and $\sigma_{H V}^{0}<-40 \mathrm{~dB}$ in mid range to far range for Etonbreen). At both test sites, i.e., Summit and Etonbreen, poor SNR levels of below $0 \mathrm{~dB}$ can locally bias the polarimetric covariance matrix and the interferometric coherences, particularly the $H V$ channel. To compensate for this, an additive noise correction was applied, as discussed in Section IV-B and Appendix B.

Simulations indicate that an $m_{H V}$ of $\sim 1$ at Summit and $\sim 1.5$ at Etonbreen would be sufficient to lower P-band $\kappa_{e} H V$ values to the inverted co-pol levels. At L-band, inverted sastrugi 


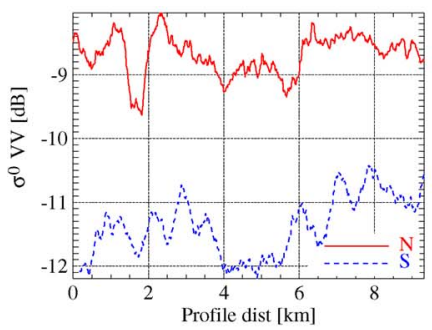

(a)

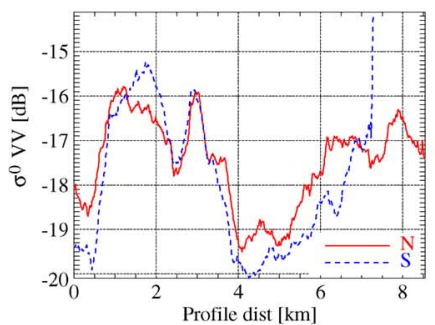

(c)

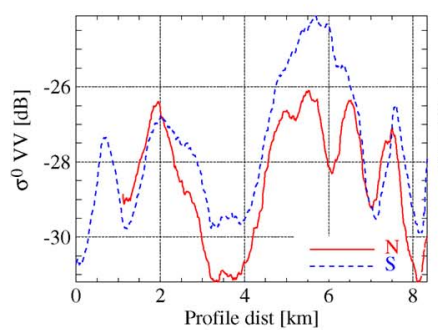

(e)

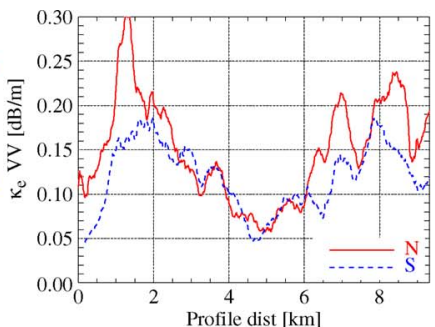

(b)

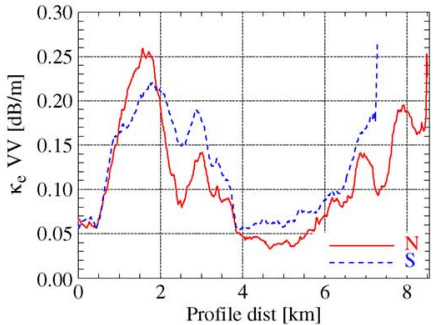

(d)

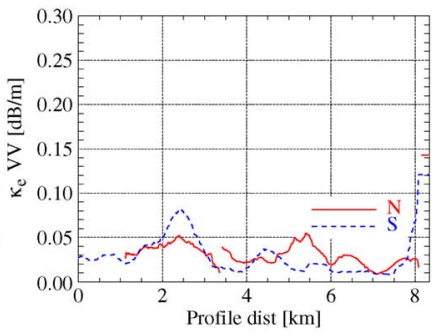

(f)
Fig. 14. Backscatter coefficients $\left(\sigma^{0}\right)$ and extinctions $\left(\kappa_{e}\right)$ at $V V$ polarization along the profiles from Figs. 11 and 12 for Summit and Etonbreen. Values for north $(\mathrm{N})$ and south $(\mathrm{S})$ geometries are shown in solid and dotted lines, respectively. At Etonbreen, no south-flying L-band passes were available for comparison. (a) Summit, L-band, $\sigma^{0}$. (b) Summit, L-band, $\kappa_{e}$. (c) Summit, P-band, $\sigma^{0}$. (d) Summit, P-band, $\kappa_{e}$. (e) Eton, P-band, $\sigma^{0}$. (f) Eton, P-band, $\kappa_{e}$.

contributions from the polarimetric decomposition are much stronger than at P-band, leading to nonzero $m_{H V}$ in Figs. 9(c) and $10(\mathrm{c})$; the additional contribution of second-order SPM terms to the surface cross-pol component would thus be less significant at this frequency.

For Etonbreen, both L-band [see Figs. 12(a)-(c) and 13(c)] and P-band [see Figs. 12(d)-(f) and 13(d)] have similar trends. Co-pol extinctions are comparable, whereas cross-pol extinctions, particularly at P-band, are elevated and decrease with increasing incidence angle, again suggesting an uncompensated ground component. However, the similarity of the co-pols indicates that the assumption of a random volume is tenable.

Despite potential differences in extinction accuracy with the incidence angle, the inverted extinctions in Figs. 11-13 are not heavily dependent on the incidence angle, and values are relatively homogeneous across the scene. Further evidence of inversion stability is given in Fig. 14, where $V V$ extinctions and backscatter values along the profiles shown in Figs. 11 and 12 have been extracted for solutions from flights both north and south of the test site, corresponding to a difference in the incidence angle of $12^{\circ}$ at Summit and $5^{\circ}$ at Etonbreen. Due to the strong similarity of the co-pol extinctions (see Figs. 11-13), plots for $H H$ are not included. In near range at Etonbreen (lefthand side of each image in Fig. 12), there are areas that cannot be inverted due to a strong surface response, for which reason a profile closer to the center of the image was selected for this test site. The GPR profiles from Fig. 6 are not used as they lie close to the center of the image, and thus, the difference in the incidence angle from north and south passes is minimal. To improve extinction results in areas of strong surface backscatter such as at Etonbreen, a more complete extinction map could be obtained by combining values from both north and south passes to fill gaps in near range.

The backscatter coefficients in Fig. 14(a), (c), and (e) are up to several decibels different for the north compared with the south images due to a varying surface contribution, particularly at L-band with large $m$ values. However, despite the difference in the radar acquisition geometry, extinctions have similar magnitudes and trends for both solutions, with mean differences on the order of $0.04 \mathrm{~dB} / \mathrm{m}$ at L-band and $0.005 \mathrm{~dB} / \mathrm{m}$ at P-band; the variable surface component has been thus successfully removed allowing identification of subsurface ice features.

There are several reasons why extinction coefficients (in certain instances) have an advantage over the use of backscattering coefficients. The extinction coefficient is more directly related to the physical properties and vertical structure of the ice volume than the backscattering coefficient, which depends on a number of parameters including terrain slope, surface properties (e.g., roughness and wind-induced features), and volume characteristics. Additionally, extinction's direct relation to the penetration depth [19] makes it a product in and of itself for interpreting differential InSAR results, which is not the case for the backscattering coefficient.

\section{VALIDATION}

The validation of inverted extinctions is made difficult due to the paucity of ground measurements and to the large penetration depths into the ice. Nevertheless, comparisons can be made to published values in the literature, as well as to the GPR data introduced in Section IV-C.

\section{A. Comparison to Published Extinction Values}

Published values include laboratory experiments on pure ice deriving the absorption extinction coefficient $\kappa_{a}$ and experimentally derived results, which include the effects of both absorption $\left(\kappa_{a}\right)$ and scattering $\left(\kappa_{s}\right)$ for a combined extinction coefficient $\kappa_{e}\left(=\kappa_{a}+\kappa_{s}\right)$. In the absence of impurities, the primary factors impacting $\kappa_{a}$ are frequency and temperature. Although, for the majority of Svalbard glaciers, the temperature regime is poorly known, borehole temperatures between $-1{ }^{\circ} \mathrm{C}$ and $-7{ }^{\circ} \mathrm{C}$ were reported in [47] at a depth of $10 \mathrm{~m}$ on the ice cap. The temperature in the upper few meters of ice is seasonally dependent, but below $\sim 10$-m-depth temperatures are expected to remain relatively stable both intra- and interannually. These borehole measurements should thus roughly coincide with the subsurface temperatures of the test sites in this paper.

Published laboratory experiments on pure ice quote absorption extinction coefficients of $0.02-0.09 \mathrm{~dB} / \mathrm{m}$ at L-band and 
P-band (lower bound [48] and upper bound [25]) for temperatures ranging from $-5{ }^{\circ} \mathrm{C}$ to $-8^{\circ} \mathrm{C}$. There is a large variation in the results dependent upon the method used, instrument accuracy, and purity of the samples with L-band extinctions slightly larger than P-band values. There has been very little research to date examining extinctions at L-band and P-band from glacier and ice sheet samples; one L-band study of GPR data from the dry snow zone of Dronning Maud Land, Antarctica [49], found extinctions of $0.29 \mathrm{~dB} / \mathrm{m}$ at $1.5 \mathrm{GHz}$ and $0.04 \mathrm{~dB} / \mathrm{m}$ at $0.9 \mathrm{GHz}$ (L-band data in this paper were collected at $1.3 \mathrm{GHz}$ ). Note that the extinctions in [49] were not defined in the rigorous sense as in (1); these were quoted as approximate depths at which there was a GPR backscatter return and not necessarily the point of $1 / e(\sim 38 \%)$ one-way power. At P-band, an extinction rate of $0.03 \mathrm{~dB} / \mathrm{m}$ was derived from GPR data in the firn zone of central Greenland [50].

Comparing these values in the literature to our experimentally derived results from the firn zone at Summit (see Fig. 11 and Table I), the averaged L-band results from the Pol-InSAR model of $\sim 0.1 \mathrm{~dB} / \mathrm{m}$ are reasonable when compared with [49], falling between the extinctions specified for 0.9 and $1.5 \mathrm{GHz}$. At P-band, there are higher extinctions $(>0.15 \mathrm{~dB} / \mathrm{m})$ in areas of concentrated potential melt structures at Summit, but background values are approximately $0.05 \mathrm{~dB} / \mathrm{m}$, in rough agreement with Paden et al. [50]. The Summit P-band extinctions are perhaps slightly higher than in [50] due to the overall greater melt at this test site and because Paden et al. [50] examined returns over the full $\sim 3 \mathrm{~km}$ ice depth in Greenland; fewer inhomogeneities are found deep in the ice and could thus result in lower extinctions.

At Etonbreen in the SI zone, extinctions at both L-band and P-band are lower than at Summit, with values of close to $0.05 \mathrm{~dB} / \mathrm{m}$ at L-band and $0.04 \mathrm{~dB} / \mathrm{m}$ at P-band (for the co-pols), with some areas of enhanced backscatter with extinctions of 0.1 to $0.15 \mathrm{~dB} / \mathrm{m}$. The L- and P-band Etonbreen values are consistent with an extinction dominated by absorption component $\kappa_{a}$, which is reasonable since, in the SI zone, potential scatterers (air bubbles and layers of changing density) are generally small and/or smooth compared with the wavelength and are less likely to generate a return in the backscatter direction than features in the firn zone. Although extinctions are dominated by a (likely constant) $\kappa_{a}$ component, the co-pol spatial variations in L- and P-band Etonbreen $\kappa_{e}$ shown in Fig. 12 are attributed to small-scale variations in the SI structure. SI forms as a result of the refreezing of water-saturated snow or ponded meltwater [18], whose formation is strongly influenced by local (even very slight) surface topography; it is enhanced on relatively flat areas allowing the ponding of meltwater [1], whereas drainage channels effectively remove meltwater and limit SI formation [51], resulting in spatially variable ice structure.

It is recognized, however, that contributions from absorption and scattering losses are difficult to separate without estimates of the ice temperature, density, grain-size variations with depth, and precise knowledge of any ice structures present in the firn. Thus, the interpretation of the exact nature of the relative $\kappa_{a}$ and $\kappa_{s}$ contributions to $\kappa_{e}$ remains ambiguous in the absence of additional in situ information.

\section{B. Comparison to GPR}

For comparison with the SAR data, the GPR vertical profiles from Fig. 7 were squared, weighted, and summed with depth to derive an effective backscattering coefficient using the method described in [52]. To remove the surface backscatter contribution and thereby isolate volume scattering, the integration of the GPR data was performed from the maximum depth $(\sim 100 \mathrm{~ns})$ to $25 \mathrm{~ns}$. Volumetric backscattering rather than GPR extinction was derived due to the shallow depths and to the presence of high-resolution ice structure and layering in the GPR profiles (see Fig. 7). The extinction model assumes a homogeneous volume with decreasing returned signal power with depth; these assumptions are not valid for the GPR profiles, although extinction may be derived for deeper profiles from, for example, sounder data as in [16] and [40].

Because the GPR data are not radiometrically calibrated, only a relative comparison between the GPR and SAR data is possible, although it can be investigated whether changes in volume scattering over the profile seen by the GPR are correlated with changes in the SAR backscattering coefficient and with inverted extinctions. Assuming uniform ice volume temperatures along the profiles (reasonable given elevation differences of less than $200 \mathrm{~m}$ along the profiles), the absorption component of the extinction will be constant, and thus, variations in $\kappa_{e}$ will be dominated by scattering (i.e., by variations in $\kappa_{s}$ attributed to the presence of localized ice structures), which should display a positive correlation with GPR volume backscattering.

In Figs. 6 and 7, it is shown that both the SAR and GPR data are extremely homogeneous over the profile acquired at Summit, making a comparison of differences in volume scattering with profile distance difficult. However, at Etonbreen, there are significant variations over the profile, and thus, the focus is on results from this test site.

The comparison is limited due to differences in frequency, depth of integration (only $9 \mathrm{~m}$ for the GPR data; see the depth scale in Fig. 7 compared with the much deeper SAR penetration depths inverted in Table II), and, most significantly, differences in viewing geometry; the GPR is nadir looking and thus has a strong specular reflection component compared with the SAR side-looking backscatter. Nevertheless, a relative comparison of GPR backscattering coefficients with the SAR data can indicate whether the volume scattering seen by the GPR is related to that from the inverted extinctions.

Fig. 15 plots scaled and normalized $\kappa_{e}, \sigma_{\mathrm{SAR}}^{0}$, and $\sigma_{\mathrm{GPR}}^{0}$ coefficients, where GPR and SAR backscatter values (in decibels) and extinctions (in decibels per meter) have been scaled to zero mean and a standard deviation of unity for comparison purposes. SAR backscatter $\sigma_{\mathrm{SAR}}^{0}$ is a function of both surface and subsurface properties, and some correlation is seen with the GPR subsurface backscatter, for example, from $5 \mathrm{~km}$ onward for L-band in Fig. 15(a). However, better agreement is observed between extinctions and GPR backscatter, particularly at L-band, which suggests that the surface component in the backscattering coefficient $\sigma_{\mathrm{SAR}}^{0}$ has been removed in the extinction estimate. At P-band, the agreement is not as close as at L-band, although this could be due to deeper penetrations at 


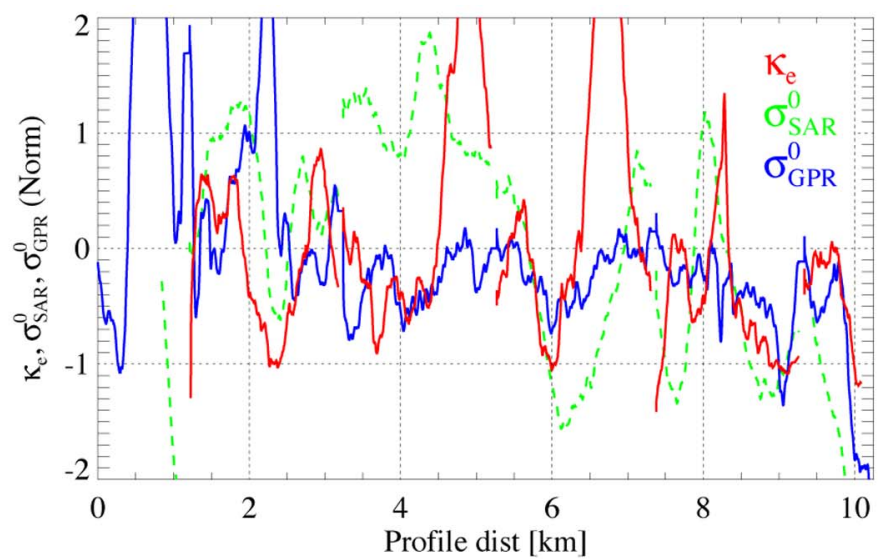

(a) Eton, L-band

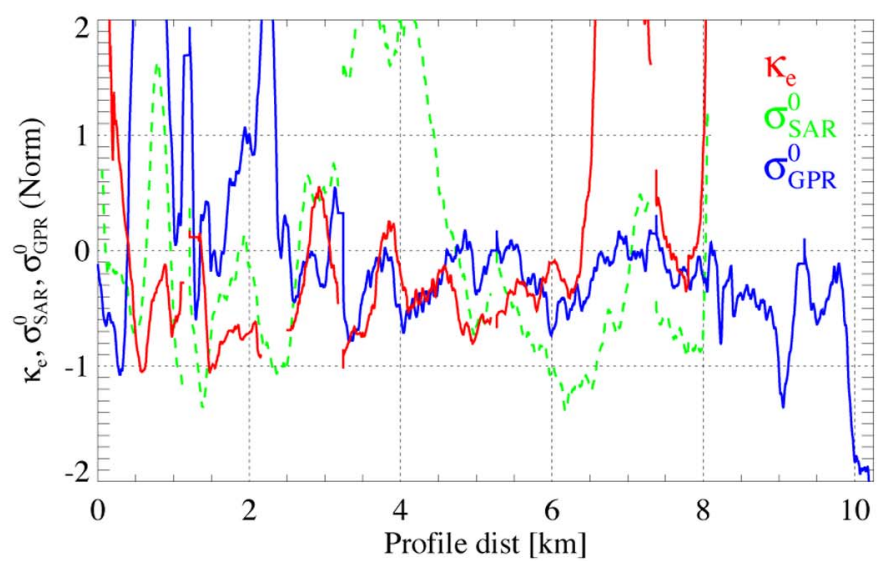

(b) Eton, P-band

Fig. 15. Normalized (red) $\kappa_{e} V V$ and (green) $\sigma_{V} V^{0}$ from SAR, and (blue) GPR $-\sigma^{0}$ profiles for Etonbreen. Values have been scaled to zero mean and unity standard deviation for comparison.

P-band contributing significant backscatter from below the range of the GPR data. A similar result is found comparing $\sigma_{\mathrm{GPR}}^{0}$ values to the L- and P-band SAR volumetric backscatter output from the polarimetric decomposition. However, as extinction estimation is the focus of this paper, it was desired to compare GPR to the extinction end product.

\section{DISCUSSION AND CONCLUSION}

In this paper, a model relating Pol-InSAR observables to glacier ice extinctions has been presented. The model has been inverted for experimental airborne data at L-band and P-band over the Austfonna ice cap, where the modeling approach has been divided into two segments: first, the volume return has been isolated through decomposition of the polarimetric covariance matrix into volume, surface, and sastrugi (oriented wind-induced) components. Ground-to-volume scattering ratios derived from the polarimetric decomposition have been then used in conjunction with Pol-InSAR coherences and an infinite uniform-volume-under-ground model to invert ice extinctions.

Ground-to-volume scattering ratios are best estimated for scenarios with a balance of surface and volume returns, i.e., for small values of $m$, favoring acquisitions at shallow incidence angles for which surface contributions are reduced. $m$ values are also frequency dependent, such that, in areas of increased volume and sastrugi scattering (e.g., the Summit test site), longer wavelengths may be favorable for decreased $m$.

Despite relatively large uncertainties in the estimated extinctions, as discussed in Section III, inverted extinctions favorably compare with existing values in the literature and correlate with GPR subsurface backscatter patterns. An important result is that the inverted extinctions are also relatively stable across a varied radar acquisition geometry, as shown by the consistency in $\kappa_{e}$ estimates from ascending and descending passes. Best results have been obtained for interferometric baselines that are large enough to minimize nonvolumetric decorrelation effects while remaining small enough to minimize the sensitivity of extinctions to errors in the input parameters and to shortcomings of the coherence model. Extinctions present an advantage over the conventional use of backscattering coefficients since, whereas backscattering coefficients are a function of both surface and subsurface glacier properties and are thus ambiguous in their interpretation, extinctions reflect properties of the underlying volume. For swath areas in mid range to far range, accuracies of $25 \%$ in extinction have been anticipated when averaging over 100 effective looks for a four-baseline inversion constraining solutions to vertical wavenumbers of $0.01 \leq k_{z} \leq 0.1$.

The proposed model is applicable for long wavelengths (L-band and P-band) and for sites with approximately uniform density profiles, negligible liquid water content, and sufficient volume scattering to obtain small ground-to-volume scattering ratios (preferably $m<20$ ). These requirements are typically met for early spring conditions in the firn and SI zones of the Austfonna glacier used in this paper, but a revised model may be required for the dry snow zones (displaying strong density contrasts) and ablation zones (having insufficient volume scattering) present at other test sites.

Although extinctions have been successfully inverted, there remain unresolved issues. A relatively simple scattering model has been implemented assuming a random distribution of volume scatterers and a uniform-volume-under-ground scenario. An important question is if the single surface layer model is appropriate or whether the layered nature of the near-surface ice volume must be considered. GPR data (although only available to a depth of $9 \mathrm{~m}$ ) show that for both test sites, there is a strong surface response at the snow-firn interface with some volume scattering beneath, and thus, the single-layer assumption would appear to be reasonable at least to the first order. However, several layers are in fact discernible in the GPR data at Summit (although their strength has been exaggerated in Fig. 7 with an exponential gain function). It is thus possible that groundto-volume scattering ratios are overestimated because returns from englacial layers are grouped, together with the snow-firn interface, to form the "ground" component during polarimetric decomposition. Observed interferometric phase centers, which are deeper than those predicted using the single surface layer model [24], could be also explained with the multilayer model.

This paper has proposed a simplified ice extinction model invertible using single-baseline Pol-InSAR data. Further work 
could improve the way multiple baselines are combined, using the additional degrees of freedom for a more realistic and, hence, complex extinction model. Due to insufficiencies in the interferometric modeling of air-snow, snow-firn, and englacial interfaces, fits of Pol-InSAR coherences over multiple baselines to the uniform-volume-under-ground model (without consideration of polarimetric backscatter and correlation properties, as performed in [35]) lead to unrealistically high extinctions when compared with published results from the literature. Extensions of this paper to a multibaseline solution should thus revisit modeling assumptions and perhaps incorporate multiple scattering layers into the coherence model.

However, the implementation of a multilayer model requires additional input parameters and/or introduces additional unknowns, including the surface roughness of each layer, layer spacing, and number of layers. Further improvements including the modeling of a nonuniform volume accounting for firn density changes with depth could be also applied, but difficulties arise in determining the test-site-dependent depth-density relationship, resulting in an overparameterization of the inversion problem. In summary, it is not clear that such models could be inverted without significant in situ data for their calibration and would thus be of limited use, although 3-D backscatter profiling at even coarse resolutions using SAR tomography [53] could be used to resolve scattering processes with depth.

Another critical issue is the assumption of a random volume in the decomposition model, which could be reconsidered in future studies. Since a random volume should have identical extinctions for all polarizations, there are inconsistencies in the modeling, but it is an important first step in removing the ground contribution to derive unbiased land ice extinctions. Future work will focus on use of the complete Pol-InSAR covariance matrix to help separate oriented surface features from volume orientations in order to explain the observed differential extinctions between polarizations, particularly at L-band, although the challenge remains of finding a valid model consistent with all amplitude and phase observables. Aside from the cross-pol, whose ground component could be improved with second-order SPM modeling, inverted extinctions at P-band appear to be nearly polarization independent, and thus, the random volume assumption is considered to be justified at this frequency.

The presented extinction model may be useful for examining the long-term variability of the polar regions by tracking interannual changes in glaciers and ice sheets, particularly areas of significant melt and drainage features. Two-dimensional extinction maps from side-looking SARs (particularly if extended to spaceborne platforms) enable simultaneous high resolution and wide area coverage compared with radar altimeters, which could open new fields of study into the temporal and finescale spatial variation of ice structure. The estimation of glacier volume parameters such as extinction using longer wavelength Pol-InSAR observables is also important for future spaceborne concepts. Potential satellite missions including Tandem-L (L-band) [54] and ESA's BIOMASS Earth Explorer proposal (P-band) [55], as well as estimates of radar altimeter and InSAR penetration biases in existing data could benefit from an increased understanding of radar observables over glacier ice.

\section{APPENDIX A \\ Derivation OF THE Volumetric COHEREnCE}

The volumetric decorrelation $\gamma_{\mathrm{vol}}$ for an infinite volume is given by the normalized Fourier transform of the volumetric radar cross section (RCS) $\sigma_{v}(z)$ integrated from $-\infty$ to 0 [15], i.e.,

$$
\gamma_{\mathrm{vol}}=\frac{\int_{-\infty}^{0} \sigma_{v}(z) e^{j k_{z \mathrm{vol}^{z} z}} d z}{\int_{-\infty}^{0} \sigma_{v}(z) d z}
$$

where $k_{z \text { vol }}$ is the vertical wavenumber in the volume

$$
\begin{aligned}
k_{z \mathrm{vol}} & =\frac{4 \pi \sqrt{\varepsilon_{r}}}{\lambda} \frac{\Delta \theta_{r}}{\sin \theta_{r}} \\
& =k_{z} \sqrt{\varepsilon_{r}} \frac{\cos \theta}{\cos \theta_{r}} .
\end{aligned}
$$

In (17), $k_{z}$ is the standard vertical wavenumber in free space [28]. Assuming the volume consists of uniformly distributed and uncorrelated scattering centers, such that the extinction coefficient is a constant, $\sigma_{v}(z)$ is an exponential, i.e.,

$$
\sigma_{v}(z)=\sigma_{v}^{0} e^{\frac{2 z \kappa_{e}}{\cos \theta_{r}}}
$$

where $\sigma_{v}^{0}$ is the average RCS per unit volume. The substitution of (18) into (16) and the evaluation of the integral yield the volumetric coherence in (4).

\section{APPENDIX B \\ COVARIANCE MATRICES FOR POlARIMETRIC DECOMPOSITION}

This section describes the covariance matrices for each contribution of the three-component decomposition described in Section II-B. Further details on the derivation of these results can be found in [10].

The covariance matrix is formed from the outer product of the lexicographic scattering vector $\vec{k}_{L}=$ $\left[S_{H H}, \sqrt{2} S_{H V}, S_{V V}\right]^{T}$ with its conjugate transpose and is given by [56], [57]

$$
\begin{aligned}
C & =\left\langle\vec{k}_{L} \vec{k}_{L}^{\dagger}\right\rangle \\
& =\left[\begin{array}{ccc}
\left\langle\left|S_{H H}\right|^{2}\right\rangle & \sqrt{2}\left\langle S_{H H} S_{H V}^{*}\right\rangle & \left\langle S_{H H} S_{V V}^{*}\right\rangle \\
\sqrt{2}\left\langle S_{H V} S_{H H}^{*}\right\rangle & 2\left\langle\left|S_{H V}\right|^{2}\right\rangle & \sqrt{2}\left\langle S_{H V} S_{V V}^{*}\right\rangle \\
\left\langle S_{V V} S_{H H}^{*}\right\rangle & \sqrt{2}\left\langle S_{V V} S_{H V}^{*}\right\rangle & \left\langle\left|S_{V V}\right|^{2}\right\rangle
\end{array}\right]
\end{aligned}
$$

where superscript $\dagger$ denotes the complex conjugate transpose, $*$ the complex conjugate only, and $\langle$.$\rangle represents ensemble$ averaging. 
The additive noise matrix $N$ in (6) has equal noise powers $n$ along the diagonal, independent of the polarization state. Assuming a zero-mean Gaussian white noise process, the noise power may be estimated using the decorrelation of the cross-pol channels using the method described in [42].

Surface Scattering: At the L- and P-band wavelengths of interest, the surface is assumed to be smooth with respect to the wavelength and is modeled using the SPM [19] giving ground covariance matrix, i.e.,

$$
C_{g}=f_{g}\left[\begin{array}{ccc}
|\beta|^{2} & 0 & \beta \\
0 & 0 & 0 \\
\beta^{*} & 0 & 1
\end{array}\right]
$$

where

$$
\beta=\frac{R_{h}}{R_{v}} e^{j\left(\phi_{h}-\phi_{v}\right)} .
$$

In (20) and (21), $f_{g}$ is the ground power coefficient, $R_{h}$ and $R_{v}$ are the Bragg coefficients for horizontally and vertically polarized waves [19], $j$ is the imaginary unit, and $\phi_{h}$ and $\phi_{v}$ are the horizontal and vertical ground phase components. $|\beta|$ is fixed to conform to the SPM using knowledge of the approximate snow and firn dielectric constants.

Volume Scattering: For simplicity and to reduce the number of unknowns, the volume is modeled as a cloud of randomly distributed dipoles (as in [36]). Accounting for transmissivity effects due to refraction at the snow-firn interface, the volume covariance matrix is given by

$$
C_{v}=f_{v}\left[\begin{array}{ccc}
T_{h}^{4} & 0 & \frac{1}{3} T_{h}^{2} T_{v}^{2} \\
0 & \frac{2}{3} T_{h}^{2} T_{v}^{2} & 0 \\
\frac{1}{3} T_{h}^{2} T_{v}^{2} & 0 & T_{v}^{4}
\end{array}\right]
$$

where $f_{v}$ is the volume power coefficient, and $T_{h}$ and $T_{v}$ are the transmission coefficients for horizontal and vertical polarizations, respectively given in [44]. The relative permittivity $\varepsilon_{r}$ required to compute transmissivities is derived from an empirical relation to firn density [41]. An approximate firn density of $\rho_{\text {firn }}=800 \mathrm{~kg} / \mathrm{m}^{3}$ yields relative permittivity $\varepsilon_{r \text { firn }}=2.8$, and assuming a snow density of $400 \mathrm{~kg} / \mathrm{m}^{3}$ gives $\varepsilon_{r}$ snow $=$ 1.7, where firn and snow densities were obtained from in situ data.

Oriented Sastrugi Field: A third component arises from an oriented sastrugi field. Sastrugi are snow dunes formed by wind deposition and erosion of the snow surface [27] and are widespread across ice sheets with high winter accumulation rates and strong winds.

Sastrugi are modeled as dipoles confined to a plane on the air-snow surface. The scatterer orientations are parameterized by angle $\nu$ measured from the horizontal polarization axis and are assumed to follow a truncated uniform distribution with center angle $\nu_{0}$ and distribution width $2 \Delta \nu$ yielding the following covariance matrix:

$$
C_{s}=\frac{f_{s}}{\Delta \nu}\left[\begin{array}{ccc}
f_{11} & f_{12} & f_{13} \\
f_{12} & 2 f_{13} & f_{23} \\
f_{13} & f_{23} & f_{33}
\end{array}\right]
$$

where

$$
\begin{aligned}
f_{11}= & 12 \Delta \nu+8 \cos \left(2 \nu_{0}\right) \sin (2 \Delta \nu)+\cos \left(4 \nu_{0}\right) \sin (4 \Delta \nu) \\
f_{12}= & -4 \sqrt{2}\left(\cos ^{4}\left(\Delta \nu-\nu_{0}\right)-\cos ^{4}\left(\Delta \nu+\nu_{0}\right)\right) \cos (\theta) \\
f_{13}= & \left(4 \Delta \nu-\cos \left(4 \nu_{0}\right) \sin (4 \Delta \nu)\right) \cos ^{2}(\theta) \\
f_{23}= & 4 \sqrt{2}\left(\sin ^{4}\left(\Delta \nu-\nu_{0}\right)-\sin ^{4}\left(\Delta \nu+\nu_{0}\right)\right) \cos ^{3}(\theta) \\
f_{33}= & \left(12 \Delta \nu-8 \cos \left(\nu_{0}\right) \sin (2 \Delta \nu)\right. \\
& \left.+\cos \left(4 \nu_{0}\right) \sin (4 \Delta \nu)\right) \cos ^{4}(\theta)
\end{aligned}
$$

and where $f_{s}$ is a scaling factor and $\theta$ is the incidence angle.

\section{ACKNOWLEDGMENT}

The authors would like to thank their partners in the IceSAR campaign including colleagues at the Norwegian Polar Institute and the University of Oslo under the direction of Prof. J. O. Hagen, particularly T. Dunse whose acquisition of the ground penetrating radar data was invaluable. The authors also thank the reviewers for their constructive comments and recommendations for this paper.

\section{REFERENCES}

[1] R. V. Engeset, J. Kohler, K. Melvold, and B. Lundén, "Change detection and monitoring of glacier mass balance and facies using ERS SAR winter images over Svalbard," Int. J. Remote Sens., vol. 23, no. 10, pp. $2023-$ 2050, Jan. 2002.

[2] D. Floricioiu, M. Eineder, H. Rott, and T. Nagler, "Velocities of major outlet glaciers of the Patagonia icefield observed by TerraSAR-X," in Proc. IEEE IGARSS, Jul. 7-11, 2008, vol. 4, pp. 347-350.

[3] R. Forster, K. C. Jezek, J. Bolzan, F. Baumgartner, and S. P. Gogineni, "Relationships between radar backscatter and accumulation rates on the Greenland ice sheet," Int. J. Remote Sens., vol. 20, no. 15/16, pp. 31313147, Jan. 1999.

[4] G. Rotschky, W. Rack, W. Dierking, and H. Oerter, "Retrieving snowpack properties and accumulation estimates from a combination of SAR and scatterometer measurements," IEEE Trans. Geosci. Remote Sens., vol. 44, no. 4, pp. 943-956, Apr. 2006.

[5] S. Oveisgharan and H. A. Zebker, "Estimating snow accumulation from InSAR correlation observations," IEEE Trans. Geosci. Remote Sens., vol. 45, no. 1, pp. 10-20, Jan. 2007.

[6] E. J. Rignot, S. J. Ostro, J. J. van Zyl, and K. C. Jezek, "Unusual radar echoes from the Greenland ice sheet," Science, vol. 261, no. 5129, pp. 1713-1713, Sep. 1993.

[7] A. F. C. Haldemann and D. O. Muhleman, "Circular-polarization radar properties of high-altitude ice: Western Kunlun Shan and central Andes," J. Geophys. Res., vol. 104, no. E10, pp. 24 075-24 095, Oct. 1999.

[8] J. Shi, J. Dozier, and H. Rott, "Snow mapping in alpine regions with synthetic aperture radar," IEEE Trans. Geosci. Remote Sens., vol. 32, no. 1, pp. 152-158, Jan. 1994.

[9] D. Floricioiu and H. Rott, "Seasonal and short-term variability of multifrequency, polarimetric radar backscatter of Alpine terrain from SIR-C/ $\mathrm{X}-\mathrm{SAR}$ and AIRSAR data," IEEE Trans. Geosci. Remote Sens., vol. 39, no. 12 , pp. 2634-2648, Dec. 2001.

[10] J. J. Sharma, I. Hajnsek, K. P. Papathanassiou, and A. Moreira, "Polarimetric decomposition over glacier ice with long-wavelength PolSAR," IEEE Trans. Geosci. Remote Sens., vol. 49, no. 1, pp. 519-535, Jan. 2011.

[11] D. Massonnet and K. L. Feigl, "Radar interferometry and its application to changes in the Earth's surface," Rev. Geophys., vol. 36, no. 4, pp. 441500, Nov. 1998

[12] I. R. Joughin, R. Kwok, and M. A. Fahnestock, "Interferometric estimation of three-dimensional ice-flow using ascending and descending passes," IEEE Trans. Geosci. Remote Sens., vol. 36, no. 1, pp. 25-37, Jan. 1998.

[13] J. A. Dowdeswell, B. Unwin, A. M. Nuttall, and D. J. Wingham, "Velocity structure, flow instability and mass flux on a large Arctic ice cap from satellite radar interferometry," Earth Planet Sci. Lett., vol. 167, no. 3/4, pp. 131-140, Apr. 1999.

[14] E. W. Hoen and H. A. Zebker, "Penetration depths inferred from interferometric volume decorrelation observed over the Greenland ice sheet," IEEE Trans. Geosci. Remote Sens., vol. 38, no. 6, pp. 2571-2583, Nov. 2000. 
[15] E. W. Hoen, "A correlation-based approach to modeling interferometric radar observations of the Greenland ice sheet," Ph.D. dissertation, Stanford Univ., Standford, CA, Mar. 2001.

[16] J. J. Sharma, "Estimation of glacier ice extinction coefficients using long-wavelength polarimetric interferometric synthetic aperture radar," $\mathrm{Ph} . \mathrm{D}$. dissertation, Karlsruher Institut für Technologie (KIT), Karlsruhe, Germany, 2010.

[17] C. H. Davis and V. I. Poznyak, "The depth of penetration in Antarctic firn at $10 \mathrm{GHz}$," IEEE Trans. Geosci. Remote Sens., vol. 31, no. 5, pp. 11071111, Sep. 1993.

[18] W. S. B. Paterson, The Physics of Glaciers, 3rd ed. Oxford, U.K.: Butterworth Heinemann, 1994.

[19] F. T. Ulaby, R. K. Moore, and A. K. Fung, Microwave Remote Sensing, Active and Passive, Volume II: Radar Remote Sensing and Surface Scattering and Emission Theory. Reading, MA: Addison-Wesley, 1982.

[20] D. G. Long and M. R. Drinkwater, "Greenland ice sheet surface properties observed by the Seasat-A scatterometer at enhanced resolution," J. Glaciol., vol. 40, no. 135, pp. 213-230, 1994.

[21] H. Rott and R. E. Davis, "Multifrequency and polarimetric SAR observations on alpine glaciers," Ann. Glaciol., vol. 17, pp. 98-104, 1993.

[22] O. Stebler, A. Schwerzmann, M. Lüthi, E. Meier, and D. Nüesch, "PolInSAR observation from an alpine glacier in the cold infiltration zone at L- and P- band," IEEE Geosci. Remote Sens. Lett., vol. 2, no. 3, pp. 357361, Jul. 2005

[23] J. Dall, K. P. Papathanassiou, and H. Skriver, "Polarimetric SAR interferometry applied to land ice: First results," in Proc. IEEE IGARSS, Seattle, WA, Jul. 6-10, 2003, vol. 3, pp. 1432-1434.

[24] J. Dall, K. P. Papathanassiou, and H. Skriver, "Polarimetric SAR interferometry applied to land ice: Modeling," in Proc. EUSAR, Ulm, Germany, May 2004, pp. 247-250.

[25] M. Tiuri, A. Sihvola, E. Nyfors, and M. Hallikaiken, "The complex dielectric constant of snow at microwave frequencies," IEEE J. Ocean. Eng., vol. OE-9, no. 5, pp. 377-382, Dec. 1984.

[26] M. Hallikainen, "Review of the microwave dielectric and extinction properties of sea ice and snow," in Proc. IEEE IGARSS, 1992, vol. 2, pp. 961-965.

[27] R. Bindschadler, "Tracking subpixel-scale sastrugi with Advanced Land Imager," IEEE Trans. Geosci. Remote Sens., vol. 41, no. 6, pp. 13731377, Jun. 2003.

[28] K. P. Papathanassiou and S. R. Cloude, "Single-baseline polarimetric SAR interferometry," IEEE Trans. Geosci. Remote Sens., vol. 39, no. 11, pp. 2352-2363, Nov. 2001.

[29] S. R. Cloude and K. P. Papathanassiou, "Polarimetric SAR inteferometry," IEEE Trans. Geosci. Remote Sens., vol. 36, no. 5, pp. 1551-1565, Sep. 1998.

[30] G. Krieger, K. P. Papathanassiou, and S. R. Cloude, "Spaceborne polarimetric SAR interferometry: Performance analysis and mission concepts," EURASIP J. Appl. Signal Process., vol. 2005, no. 1, pp. 3272-3292, Jan. 2005.

[31] F. Gatelli, A. M. Guarnieri, F. Parizzi, P. Pasquali, C. Prati, and F. Rosca, "The wavenumber shift in SAR interferometry," IEEE Trans. Geosci. Remote Sens., vol. 32, no. 4, pp. 855-865, Jul. 1994.

[32] T. Dunse, T. V. Schuler, J. O. Hagen, T. Eiken, O. Brandt, and K. A. Høgda, "Recent fluctuations in the extent of the firn area of Austfonna, Svalbard, inferred from GPR," Ann. Glaciol., vol. 50, no. 50, pp. 155-162, Mar. 2009.

[33] J. Dall, "InSAR elevation bias caused by penetration into uniform volumes," IEEE Trans. Geosci. Remote Sens., vol. 45, no. 7, pp. 2319-2324, Jul. 2007.

[34] Wolfram Mathematica 8, Wolfram, Champaign, IL, 2011

[35] J. J. Sharma, I. Hajnsek, and K. P. Papathanassiou, "Multi-frequency Pol-InSAR signatures of a subpolar glacier," in Proc. 3rd Int. Workshop PolInSAR, Frascati, Italy, Jan. 22-26, 2007, pp. 1-8.

[36] A. Freeman and S. L. Durden, "A three-component scattering model for polarimetric SAR data," IEEE Trans. Geosci. Remote Sens., vol. 36, no. 3 , pp. 963-973, May 1998.

[37] S. Oveisgharan, "Estimating snow accumulation from InSAR correlation observations," Ph.D. dissertation, Stanford Univ., Standord, CA, Sep. 2007

[38] J. Shi, J. Du, H. Rott, T. Nagler, and K. Morrison, "Snow water equivalence retrieval using X and Ku band dual-polarization radar," in Proc. 5th Int. Symp. Retrieval Bio-Geophys. Parameters SAR Data Land Appl., Bari, Italy, Sep. 25-28, 2007.

[39] M. S. Seymour and I. G. Cumming, "Maximum likelihood estimation for SAR interferometry," in Proc. IEEE IGARSS, 1994, pp. 2272-2275.

[40] J. J. Sharma, I. Hajnsek, and K. P. Papathanassiou, "Long-wavelength Pol-InSAR for glacier ice extinction estimation," in Proc. Conf. EUSAR, Aachen, Germany, Jun. 6-10, 2010, pp. 325-328.
[41] A. Kovacs, A. J. Gow, and R. M. Morey, "The in-situ dielectric constant of polar firn revisited," Cold Regions Sci. Technol., vol. 23, no. 3, pp. 245256, May 1995.

[42] I. Hajnsek, E. Pottier, and S. R. Cloude, "Inversion of surface parameters from polarimetric SAR," IEEE Trans. Geosci. Remote Sens., vol. 41, no. 4, pp. 727-744, Apr. 2003.

[43] A. Taurisano, T. V. Schuler, J. O. Hagen, T. Eiken, E. Loe, K. Melvold, and J. Kohler, "The distribution of snow accumulation across Austfonna ice cap Svalbard: direct measurements and modeling," Polar Res., vol. 26, no. 1 , pp. 7-13, Mar. 2007

[44] F. T. Ulaby, R. K. Moore, and A. K. Fung, Microwave Remote Sensing, Active and Passive, Volume I: Fundamentals and Radiometry. Reading, MA: Addison-Wesley, 1981

[45] S. G. Warren and R. E. Brandt, "Optical constants of ice from the ultraviolet to the microwave: a revised compilation," J. Geophys. Res., vol. 113, no. 14, pp. D14220-1-D14220-10, Jul. 2008.

[46] C. Mätzler, "Improved Born approximation for scattering of radiation in a granular medium," J. Appl. Phys., vol. 83, no. 11, pp. 6111-6117, Jun. 1998.

[47] J. L. Bamber, "Internal reflecting horizons in Spitsbergen glaciers," Ann. Glaciol., vol. 9, pp. 5-10, 1987.

[48] J. A. Dowdeswell and S. Evans, "Investigations of the form and flow of ice sheets and glaciers using radio-echo sounding," Rep. Progress Phys., vol. 67, no. 10, pp. 1821-1861, Oct. 2004

[49] P. Holmlund, M. Nyman, R. Pettersson, K. Gjerde, N. Gundestrup, M. Hansson, E. Isaksson, L. Karlöf, J.-G. Winther, F. Pinglot, C. Reijmer, M. Thomassen, R. van de Wal, C. van der Veen, and F. Wilhelms, "Spatial gradients in snow layering and $10 \mathrm{~m}$ temperatures at two EPICA-Dronning Maud Land (Antarctica) pre-site-survey drill sites," Ann. Glaciol., vol. 30, no. 1, pp. 13-19, Jan. 2000.

[50] J. D. Paden, C. T. Allen, S. Gogineni, K. C. Jezek, D. Dahl-Jensen, and L. B. Larsen, "Wideband measurements of ice sheet attenuation and basal scattering," IEEE Geosci. Remote Sens. Lett., vol. 2, no. 2, pp. 164-168, Apr. 2005.

[51] K. Langley, "Glacier subsurface interpretation combining ground penetrating radar and satellite synthetic aperture radar," Ph.D. dissertation, Faculty of Math. and Nat. Sci., Univ. Oslo, Oslo, Norway, 2007.

[52] K. Langley, S. E. Hamran, K. A. Hogda, R. Storvold, O. Brandt, J. O. Hagen, and J. Kohler, "Use of C-band ground penetrating radar to determine backscatter sources within glaciers," IEEE Trans. Geosci. Remote Sens., vol. 45, no. 5, pp. 1236-1246, May 2007.

[53] A. Reigber and A. Moreira, "First demonstration of airborne SAR tomography using multibaseline L-band data," IEEE Trans. Geosci. Remote Sens., vol. 38, no. 5, pp. 2142-2152, Sep. 2000.

[54] A. Moreira, G. Krieger, I. Hajnsek, K. Papathanassiou, M. Eineder, F. De Zan, M. Younis, and M. Werner, "Tandem-L: Monitoring the Earth's dynamics with InSAR and Pol-InSAR," in Proc. 4th Int. Workshop PolInSAR, Frascati, Italy, Jan. 26-30, 2009, pp. 1-5.

[55] M. Davidson, A. Thompson, and C.-C. Lin, Candidate Earth Explorer Core Mission Report for Assessment: BIOMASS, Eur. Space Agency, Paris, France, Tech. Rep. ESA SP-1313/2. [Online]. Available: http:// www.congrex.n1/09c01/

[56] S. R. Cloude, Polarisation: Applications in Remote Sensing. New York: Oxford Univ. Press, 2010.

[57] J.-S. Lee and E. Pottier, Polarimetric Radar Imaging: From Basics to Applications. Boca Raton, FL: CRC Press, 2009.

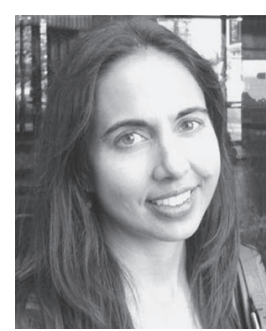

Jayanti J. Sharma (M'10) received the B.Sc. (with distinction) and M.Sc. degrees in geomatics engineering from the University of Calgary, Calgary, $\mathrm{AB}$, Canada, in 2002 and 2005, respectively, and the Eng.Dr. degree (with honors) in electrical engineering from the Karlsruhe Institute of Technology, Karlsruhe, Germany, in 2010.

From 2003 to 2004, she was with the Radar Systems Group, Defence R\&D Canada, Ottawa, and from 2005 to 2010, she was with the Microwaves and Radar Institute, German Aerospace Center (DLR), Oberpfaffenhofen, Germany. She is currently a Research Analyst with the R\&D group, MDA Systems Ltd., Vancouver, Canada. Her research interests include radar polarimetry, polarimetric synthetic aperture radar (SAR) interferometry, persistent scatterer interferometry, and remote sensing of the cryosphere.

Dr. Sharma was a recipient of the Best Student Paper Award of the European SAR Conference (EUSAR) in 2010 


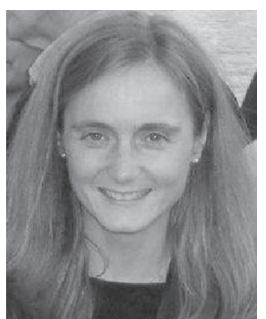

Irena Hajnsek (AM'01-M'06-SM'09) received the Dipl. degree (honors) from the Free University of Berlin, Berlin, Germany, in 1996 and the Dr. degree (honors) from the Friedrich Schiller University of Jena, Jena, Germany, in 2001.

From 1996 to 1999, she was with the Microwaves and Radar Institute, German Aerospace Center (DLR-HR), Oberpfaffenhofen, Germany, where she is currently the Head of the Polarimetric Synthetic Aperture Radar (SAR) Interferometry Research Group. From 1999 to 2000, she has been with the Institut d'Electronique et de Télécommunications de Rennes, University of Rennes 1, France, for ten months and with the Applied Electromagnetics (AEL), St. Andrews, Scotland, for four months, in the frame of the European Commission - Training and Mobility of Researchers Radar Polarimetry Network. In 2005, she was a Guest Scientist with the University of Adelaide, South Australia, for six weeks. She is the Science Coordinator of the German satellite mission TanDEM-X. Since November 2009, she has been a Professor of Earth observation with the Eidgenössische Technische Hochschule Zürich Institute of Environmental Engineering, Zurich, Switzerland. Her main research interests are in electromagnetic propagation and scattering theory, radar polarimetry, SAR and interferometric SAR data processing techniques, and environmental parameter modeling and estimation.

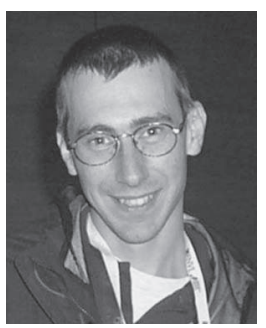

Konstantinos P. Papathanassiou (M'02-SM'03) received the Dipl.Ing. and Dr. degrees (both honors) from the Technical University of Graz, Austria, in 1994 and 1999, respectively.

From 1992 to 1994 , he was with the Institute for Digital Image Processing (DIBAG), Joanneum Research, Graz. Between 1995 and 1999, he was with the Microwaves and Radar Institute (HR), German Aerospace Center (DLR), Oberpfaffenhofen, Germany, where he has been a Senior Scientist leading the Information Retrieval Research Group since October 2000. From 1999 to 2000, he was an EU Postdoctoral Fellow with the Applied Electromagnetics (AEL), St. Andrews, Scotland. His main research interests are in polarimetric and interferometric processing and calibration techniques, polarimetric SAR interferometry, and quantitative parameter estimation from SAR data, as well as in SAR mission design and SAR mission performance analysis.

Dr. Papathanassiou was a recipient of the IEEE Geoscience and Remote Sensing Society International Geoscience and Remote Sensing Symposium (IGARSS) Symposium Prize Paper Award in 1998, the Best Paper Award of the European SAR Conference (EUSAR) in 2002, and the DLR science award in 2002 .

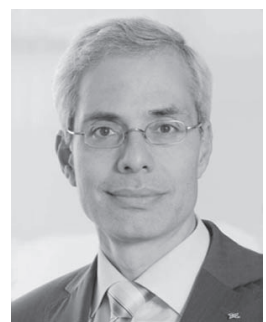

Alberto Moreira (S'96-F'04) received the B.S.E.E. and M.S.E.E. degrees from the Aeronautical Technological Institute (ITA), São José dos Campos, Brazil, in 1984 and 1986, respectively, and the Eng.Dr. degree (with honors) from the Technical University of Munich, Munich, Germany, in 1993.

From 1996 to 2001, he was the Chief Scientist and Engineer with the Synthetic Aperture Radar (SAR) Technology Department, German Aerospace Center (DLR), Oberpfaffenhofen, Germany. Under his leadership, the DLR airborne SAR system has been upgraded to operate in innovative imaging modes such as polarimetric SAR interferometry and SAR tomography. Since 2001, he has been the Director of the Microwaves and Radar Institute, DLR. The Institute contributes to several scientific programs and space projects for actual and future airborne and spaceborne SAR missions such as TerraSAR-X, TanDEM-X, and Sentinel-1. The mission TanDEM-X, led by his Institute, has successfully started the operational phase in December 2010. He is the Initiator and Principal Investigator for this mission. Since 2003, he has been a Full Professor with Karlsruhe Institute of Technology, Karlsruhe, Germany, in the field of microwave remote sensing. He has more than 300 publications in international conferences and journals. He is the holder of 15 patents in the radar and antenna field. His professional interests and research areas encompass radar end-to-end system design and analysis, innovative microwave techniques and system concepts, signal processing, and remote sensing applications.

Dr. Moreira is a member of the IEEE Geoscience and Remote Sensing Society (GRSS) Administrative Committee (1999-2001, 2004-2013, 2010 as President, 2011-2013 as Past President). He was the Founder and Chair of the GRSS German Chapter (2003-2008) and an Associate Editor for the IEEE Geoscience And Remote Sensing Letters (2003-2007) and the IEEE Transactions on Geoscience and Remote Sensing (2005-2011). He and his colleagues were recipients of the GRSS Transactions Prize Paper Awards in 1997, 2001, and 2007, and the IEEE W.R.G. Baker Award in 2012. He was also the recipient of the DLR Science Award (1995), the IEEE Nathanson Award for the Young Radar Engineer of the Year (1999), and the IEEE Kiyo Tomiyasu Field Award (2007). He served as a member of the Board of Directors of the Information Technology Society of the German Association for Electrical, Electronic, and Information Technologies (2003-2008) and as the Chair of the Scientific and Technical Council of DLR (2009-2011). He has contributed to the successful series of the European SAR conferences (EUSAR) since 1996 as a member of the Technical Program Committee, Technical Chairman (2000), Awards Chairman (2002-2004), General Chairman (2006), and Cochairman (2008), and has served as General Cochair for IGARSS' 12 in Munich. 